T. Ly

Taxes, traffic jam and spillover in the metropolis 


\title{
Taxes, traffic jam and spillover in the metropolis
}

\author{
Tidiane $\mathrm{Ly}^{\star}$
}

September, 2019

\begin{abstract}
This paper studies local governments' public policies in a metropolitan area plagued by traffic congestion, where both residents and workers consume local public goods. We develop a new spatial sub-metropolitan tax competition model which features a central city surrounded by suburban towns linked by mobile capital and mobile residents who commute to work. We show that Pareto-efficiency is achieved if towns can retain their workers using labor subsidies. Otherwise, traffic congestion in the city is inefficiently high and local governments respond by setting inefficient public policies: (i) the city over-taxes capital and under-taxes residents, which leads to too little capital and too many residents in the city; (ii) local public goods are under-provided in the city and over-provided in the towns.
\end{abstract}

Keywords: Tax competition; Urban economics; Traffic congestion; Public goods; Mobility

JEL: H71; H72; R50; R51

Supplementary material An online appendix is available here .

${ }^{\star}$ Università della Svizzera italiana. Email: tidiane.ly@usi.ch.

I thank Pierre-Philippe Combes, Florence Goffette-Nagot, William Hoyt, Étienne Lehmann, Thierry Madiès, Steeve Mongrain, Raphaël Parchet, Sonia Paty, Stéphane Riou, Kurt Schmidheiny, Elisabet ViladecansMarsal and John D. Wilson for comments and suggestions on earlier drafts. I also thank participants in the IEB Workshop on Taxation and Social Expenditure (Barcelona), French Economic Association Meeting (Orléans), GATE Public Policy and Space Seminar (Lyon), Swiss Workshop on Local Public Finance and Regional Economics (Lugano), Seminar at the Università della Svizzera italiana3++ and PEARL Workshop (Zermatt) for their comments. Financial support from Région Auvergne-Rhône-Alpes (ARC 7) is gratefully acknowledged. 


\section{Introduction}

By $2100,85 \%$ of the world's population is expected to live in metropolitan areas (MAs) (UN, 2013). ${ }^{1}$ Today, this figure already reaches more than $50 \%$ of the world's population and roughly $80 \%$ of the OECD countries' population. Meanwhile, the economic strength of numerous MAs is comparable to that of countries. MAs cover only $4 \%$ of the land area in the OECD countries but account for $55 \%$ of their GDP (OECD, 2015). Because MAs are areas of residence for most people and are creators of substantial economic wealth, their governance is a paramount concern for policy makers worldwide. The French President Nicolas Sarkozy's statement is illustrative: "The Greater Paris is at the core of our strategy of attractiveness and economic recovery. This project concerns all elected representatives." ${ }^{2}$

The gouvernance of MAs has two outstanding features compared to country governance. First, MAs are characterized by competition among many sub-metropolitan or local governments (e.g. counties, municipalities, districts, and townships) for mobile jobs and mobile residents. The governance of MAs is split among numerous local governments which often have significant autonomy to raise local revenue from residential, business and property taxes for example, to finance a range of public services such as schools, amenities (e.g. public parks) and safety. ${ }^{3}$ Mobility of private agents and autonomy of local public policy are a fertile ground for competition among local governments.

Second, MAs are characterized by strong agglomeration of jobs in MA centers and high mobility of households as residents and workers. Typically, MAs are composed of a large central city surrounded by numerous small suburban towns. Many workers are attracted by access to jobs and high wages in the central cities which cluster most activities. This concentration of workers (and often also residents) in the central cities creates negative agglomeration externalities such as congestion on amenities and public goods/services and various urban disturbances (noise, waste, etc.). Expensive housing in the city spurs many residents to settle in suburban towns where rents are more affordable. ${ }^{4}$ These suburbanites are often obliged to undertake long commutes to work in the city, which generate negative commuting externalities such as traffic congestion and air pollution. ${ }^{5}$

1 MAs are urban agglomerations with more than 500000 inhabitants (OECD, 2015).

2 Speech presenting the Greater Paris project delivered on April 29, 2009.

3 Brülhart et al. (2015) report that among the 10 most fragmented OECD MAs, a MA includes 542 local governments on average. They surveyed 40 OECD and non-OECD countries, and show that on average, $10 \%$ of total national tax revenue is collected locally.

4 For example, in French MAs the land price of the most central parcels is roughly $85 \%$ higher than the price in the most peripheral areas (Combes et al., 2018).

5 For instance, about half the workforces of London and Budapest spend more than 45 minutes commuting daily (OECD, 2015). 
Little is known about how competing local governments (hereafter municipalities) handle these negative externalities typical of MAs. The purpose of this paper is to enhance our understanding of municipality public policy in the face of over-concentration of jobs in the central business district of a MA. We focus on traffic congestion which, although "probably the most important type of negative externality in the cities" (Fujita, 1989, p. 258), has received little attention from economists interested in local public policies. ${ }^{6,7}$

This paper investigates (i) how traffic congestion affects local public policies and, as a corollary, (ii) which local policy instruments are the most relevant to tackle traffic congestion. We develop an original spatial urban tax competition model which considers a MA consisting of a set of municipalities: a large city surrounded by numerous small towns. Residents and business capital are mobile across municipalities. Households and firms compete for land. Households commute to work and incur commuting costs which include traffic congestion costs. Competing municipalities have access to several local policy instruments:

1. A tax on mobile capital and a head tax on mobile residents. These taxes capture the important features of local residential and business taxation in many countries; they are the most studied taxes in the tax competition literature. ${ }^{8}$

2. Two key instruments allow municipalities to influence directly the number of workers in their jurisdictions, and consequently, the level of traffic congestion incurred by their residents: (i) a labor tax/subsidy which is based on the workforce employed in the municipality; (ii) the provision of public goods which generate spillovers due to commuting. The model allows households to consume local public goods not only as residents but also as workers. While there are some local public goods that benefit only to local residents (e.g. local public schools), many are consumed also by local workers potentially commuting from other jurisdictions (e.g. safety, street cleaning and road conditions). These public goods make municipalities more attractive as workplaces and thus increase local traffic congestion.

6 In 2018, in the ten most congested European cities, the overall travel time was $41 \%$ higher than in a free flow situation which represented a $2 \%$ rise compared to 2017 . This figure rose to $69 \%$ and $77 \%$ during the morning and the evening peaks respectively (TomTom, 2018). This has not escaped the attention of policy makers, including Valérie Pécresse, President of the Paris Region who stated that "the inhabitants of the Paris Region are obsessed with spending less time in traffic jams" (2/6/2019).

7 Most of our conclusions also apply to the other externalities mentioned above. Formal modeling of air pollution induced by commuting is very close to our proposed modeling of traffic congestion (see e.g. DenantBoèmont et al., 2018). Besides, a previous version of this paper (Ly, 2018b) considers the case of negative agglomeration externalities from public good congestion induced by commuters and provides findings in line with those in the present paper.

8 The model also includes a tax on immobile land whose role is to allow municipalities to balance their budget. It is not the primary interest of the paper. 
The main results of the paper are summarized below.

1. If towns can retain part of their workers using labor subsidies, the decentralized equilibrium is Pareto-efficient. As intermediate outputs, the resulting original first-best local policies are characterized: public good provision optimally internalizes residents' and commuters' preferences; residential taxes guarantee optimal access to business districts; capital is not taxed.

This result highlights the key role of local labor subsidies in the regulation of traffic congestion in MAs. However, in practice, this instrument is generally not available to municipalities for three main reasons. First, subsidies are often considered violations of competition rules. Therefore, legislation in the European Union, Canada, and Australia for example, heavily limits use of subsidies (OECD, 2010; Thomas, 2010). ${ }^{9}$ Second, subsidies are expensive. On the contrary, local labor taxation is often enacted as a budgetary tool to supplement other local revenue sources. For example, the introduction of payroll taxes in San Francisco in 1970 followed this logic (Sherwood-Call, 1986). ${ }^{10}$ Third, competition among local governments can lead to a subsidy race leading to rentseeking behavior by firms (Tannenwald, 2002).

2. If towns are not allowed to subsidize labor, traffic congestion in the city becomes exessive, and local governments respond by setting inefficient second-best public policies: (i) the city over-taxes capital which leads to too little capital in the city; (ii) the city undertaxes residents which leads to too many residents in the city; (iii) in the presence of commuting-induced spillovers, local public goods are under-provided by the city and over-provided by the towns.

In sum, if towns cannot retain their workers through the use of subsidies, the central business district (CBD) attracts too many workers from the suburbs, leading to severe traffic congestion in the city. The municipalities then use the other policy instruments to dampen this excessive congestion: the city limits the size and attractiveness of the

9 In several US states, local governments are allowed to provide firms with development subsidies such as tax breaks, low-cost loans, grants, infrastructure support and low-cost land (Warner and Zheng, 2013). Development subsidies differ from the flat rate subsidies considered in this paper which are based on the municipality's total workforce. Development subsidies are bilateral commitments involving a local government and a firm. Since they are at the discretion of local politicians, they tend to favor big and highly visible projects at the expense of less visible ones (Elkin, 2015). Moreover, since these subsidies are based on ex-ante agreements, once established in the municipality, the firm might not fulfill its promises related to job creation or other performance criteria (Sullivan and Green, 1999).

${ }^{10}$ See Sjoquist and Stoycheva (2012) for an exhaustive list of the US states whose local governments use labor taxation. In France, labor was taxed by municipalities from 1975 to 1999 (Bouvier, 2004). Peralta (2007) reports on cases in Australia, Austria, Greece, Korea and Mexico. 
CBD, while the towns make their secondary business districts (SBDs) more attractive. This result highlights in particular, the detrimental role of commuting-induced spillovers which amplify the damage caused by traffic congestion by spurring the municipalities to engage in inefficient public good provision.

The paper updates our understanding of the governance of MAs in the context of typical negative externalities such as traffic congestion, pollution and other disturbances due to the agglomeration of jobs in MA centers and household mobility. The analysis suggests that local governments may be using many of their policy instruments to help to tackle these externalities. However, national governments often fail to give local authorities an important role to address these externalities; most political solutions so far are either national — e.g. road tolls and gasoline/green taxation (Pigou, 1912; Walters, 1961; Vickrey, 1963) — or regional - e.g. integrated public transport provision (Preston, 2012). Further decentralization of the fight against MA negative externalities could be fruitful. Traffic jams and CO2 emissions, for instance, can vary spatially to a significant extent within a single MA. Thus, local governments which are better informed about voters' preferences and habits could be more flexible and would be able to better target these externalities than national or regional governments. This echoes Oates's (1972) decentralization theorem.

The main policy recommendation to emerge from the analysis is that suburban towns should be allowed more leeway to retain their workers which might help to unclog MA roads and reduce externalities such as air pollution. Local labor subsidies which are usually missing in local policy instrument sets, could be an appropriate tool for this task. More generally, the paper suggests that addressing the externalities typical of MAs will require the development of truly polycentric MAs by encouraging the growth of strong secondary economic poles. This recommendation is in line with Cavailhes et al. (2007); our paper stresses that local governments could play an important role in this reshaping of MAs.

The paper is organized as follows. Section 2 reviews the related literature. Section 3 introduces the model. Section 4 presents the optimal public policy rules for a city and its surrounding towns with and without access to labor taxes/subsidies. Section 5 provides a numerical illustration. Section 6 discusses the results. Section 7 concludes.

\section{Related literature}

This paper contributes to several literature streams. It is novel in proposing the inclusion of a spatial urban structure (e.g. Fujita, 1989) in the standard capital tax competition model developed by Zodrow and Mieszkowski (1986) and Wilson (1986). Thus, it links the local public 
economics (LPE) and the urban economics (UE) literatures. ${ }^{11,12}$ The proposed model is also one of the first to include both inter-jurisdictional residential mobility and commuting in a capital tax competition framework à la Zodrow and Mieszkowski (1986). ${ }^{13}$ It links capital tax competition models with residential mobility which exclude commuting (e.g. Wilson, 1995; Brueckner, 2000) to models that include commuting but ignore residents' mobility across jurisdictions (e.g. Braid, 1996, 2000; Peralta, 2007). Finally, our study of local government responses to traffic congestion links the LPE literature and the transport economics literature (e.g. Parry, 2002; Rouwendal and Verhoef, 2006) which tends to consider traffic congestion from a national/regional government perspective.

Recent work on LPE reveals a trend towards inclusion of more real-life features of MAs in the tax competition model à la Zodrow and Mieszkowski (1986). First, following Braid (2000), some papers (e.g. Peralta, 2007; Legras, 2019) include costly commuting in the tax competition model. ${ }^{14}$ Commuting costs are purely distance costs and do not include traffic congestion; commuters do not inflict externalities on one another. Second, efforts have been devoted to include a core-periphery structure in tax competition models (Janeba and Osterloh, 2013; Gaigné et al., 2016), accounting for the fact that MAs are typically composed of a central city surrounded by suburban towns. Traffic congestion stands at the crossroads of these two approaches: it involves commuting costs typically incurred by suburbanites commuting to the MA center.

This paper allows commuters to consume local public goods at their workplace. ${ }^{15}$ Since Gordon (1983), the standard way to model local public good spillovers is to assume that public goods provided in a jurisdiction benefit indiscriminately all residents from neighboring jurisdictions (e.g. Wellisch, 1993). In practice, commuters benefit more than non-commuters

${ }^{11}$ The LPE literature might be viewed by some to be a strand of the UE literature. However, these two bodies of work are complementary. While LPE models consider endogenous local governments and generally ignore the spatial dimension of MAs, UE models consider local government choices as exogenous but pay particular attention to the spatial features of MAs.

${ }^{12}$ Gaigné et al. (2016) proposes a tax competition model with a spatial urban structure. Our model is closer to the standard tax competition models in that it includes endogenous public good provision and taxable mobile capital which are probably the most prevalent features in the tax competition literature.

${ }^{13}$ To our knowledge, only three recent papers account for capital, residents' and workers' mobility: Ly (2018a), Ly and Paty (2019) and Agrawal et al. (2019). The paper by Agrawal et al. is particularly important and describes how fiscal externalities and strategic behavior emerge when jurisdictions are atomistic in the capital market but have market power in the labor market.

${ }^{14}$ Since Braid (1996), costless commuting is more common in tax competition models. See e.g. Kächelein (2014), Sas (2017) and Ly (2018a).

${ }^{15}$ In most models with commuting (e.g. Braid, 1996, 2000; Ly, 2018a), residents and workers are disconnected so that commuters are reduced purely to production factors which by nature, neither consume public goods nor pay taxes. In an extension of their analysis, Gaigné et al. (2016) consider suburban commuters' consumption of public goods in the city, but public good provision is fixed exogenously. 
from neighboring jurisdictions' public goods. Our modeling of spillovers induced by commuting reflects this. Moreover, workers' consumption of public goods also reduces the traditional divide between public goods consumed by households and public inputs which benefit firms as is the focus in Matsumoto $(1998,2000)$.

\section{The model}

This section presents the model used for the analysis. Subsection 3.1 describes the model basic economic and spatial structure and introduces traffic congestion, the central externality in this paper. Subsection 3.2 describes households' behavior and introduces the commuting spillover externality. Subsection 3.3 describes how firms choose their inputs and compete with households for land. Subsection 3.4 derives the location system which characterizes the distribution of capital, residents and workers in the MA resulting from subsections 3.1 to 3.3.

\subsection{Metropolitan structure and commuting costs}

The economy consists of a MA composed of $n+1$ municipalities: one central city $c$ and $n$ symmetric suburban towns $s_{i}$ with $i=1, \ldots, n$. Residents, workers and business capital are mobile across municipalities. City and towns differ in two respects.

First, the MA is endowed with a hub-and-spoke commuting transportation network (Gaigné et al., 2016) which means that the $n$ towns $s_{i}$ are connected only to the city $c$, while the city has direct access to all of the towns in the MA. Therefore, having chosen a residence location, an individual living in town $s_{i}$ can work in her home town $s_{i}$ or in the city $c$. All residents living in $c$ work in $c$. This MA structure is aimed at capturing the fact that suburbanites usually hesitate between working in the city or in their home town. Commuting from the city to the suburb or from one suburban town to another similar suburban town is less frequent.

Second, city and towns differ in size as specified in the following assumption:

\section{Assumption 1 (Size).}

(i) The city is sufficiently large to directly influence all the town variables.

(ii) The towns are atomistic; they cannot influence the variables in other municipalities.

Assumption 1 is in line with patterns observed in most MAs which are characterized by strong size asymmetry between city and towns as documented in Brülhart et al. (2015). ${ }^{16}$ The paper adopts the following notations, for each municipality $j, j^{\prime} \in\left\{c ; s_{i}\right\}$ :

\footnotetext{
${ }^{16}$ Brülhart et al. (2015) report that Paris, Hamburg, Vienna and New York for example, have respectively 268, 229, 199 and 179 times more population than the average populations of the municipalities in their MAs.
} 
- $R_{j}$ : number of residents living in $j$,

- $W_{j}$ : number of workers employed in $j$,

- $W_{j j^{\prime}}$ : number of residents living in $j$ and working in $j^{\prime}$,

- $K_{j}$ : amount of business capital used in $j$,

- $L_{j}$ : amount of business land used in $j$,

- $\mathcal{L}_{j}$ : land endowment of municipality $j$,

- $\mathcal{P}$ : population of the MA,

- $\mathcal{K}$ : capital endowment of the MA,

where $R_{j}, W_{j}, W_{j j^{\prime}} K_{j}$ and $L_{j}$ are endogenous variables of the model, while $\mathcal{L}_{j}, \mathcal{P}$ and $\mathcal{K}$ are exogenously fixed. The capital resource constraint is: ${ }^{17}$

$$
K_{c}+\sum_{i=1}^{n} K_{s_{i}}=\mathcal{K}
$$

Fixed MA capital stock captures the fact that large cities often have market power in the capital market. ${ }^{18}$ The results do not change with any fixed number $m>1$ of symmetric MAs linked by capital and residential mobility sharing a fixed capital stock. Recalling that a proportion of the residents of $s_{i}$ work in $c$ whereas none of the residents of $c$ work in $s_{i}$, we have:

$$
R_{s_{i}}=W_{s_{i} c}+W_{s_{i} s_{i}}, \quad W_{s_{i}}=W_{s_{i} s_{i}} .
$$

Each individual is assumed to consume a single unit of land, so that local land market clearing for each municipality $j \in\left\{c ; s_{i}\right\}$ requires:

$$
R_{j}+L_{j}=\mathcal{L}_{j}
$$

The numbers of residents and workers may not coincide within a municipality but they do coincide at the level of the MA since each individual chooses a workplace within the MA. The population and workforce resource constraints are:

$$
R_{c}+\sum_{i=1}^{n} R_{s_{i}}=\mathcal{P}
$$

\footnotetext{
${ }^{17}$ For ease of reference, the key equilibrium conditions are numbered (e.1), (e.2), etc..

${ }^{18}$ The sources of this market power are various. While in practice not all capital in a MA or region is fixed, a non negligible share of the savings of the MA citizens is channeled to regional banks which invest primarily in regional firms (Janeba and Osterloh, 2013). In addition, some cities such as New-York, Paris and Singapore are international financial centers and concentrate a significant share of the global capital stock.
} 


$$
W_{c}+\sum_{i=1}^{n} W_{s_{i}}=\mathcal{P} .
$$

Jobs are concentrated in the CBD of the MA, as postulated in:

Assumption 2 (Concentration). Assume that the city employs at least one-third of the MA workers:

$$
W_{c}>\frac{\mathcal{P}}{3},
$$

which is equivalent to $W_{c}>\sum_{i=1}^{n} W_{s_{i}} / 2$ and at equilibrium $W_{c} / n>W_{s_{i}} / 2$ since the towns are symmetric.

Assumption 2 is theoretically relevant for studying traffic congestion and is probably the most common case in practice. ${ }^{19,20}$ Subsection 6.2 discusses our results if this assumption does not hold.

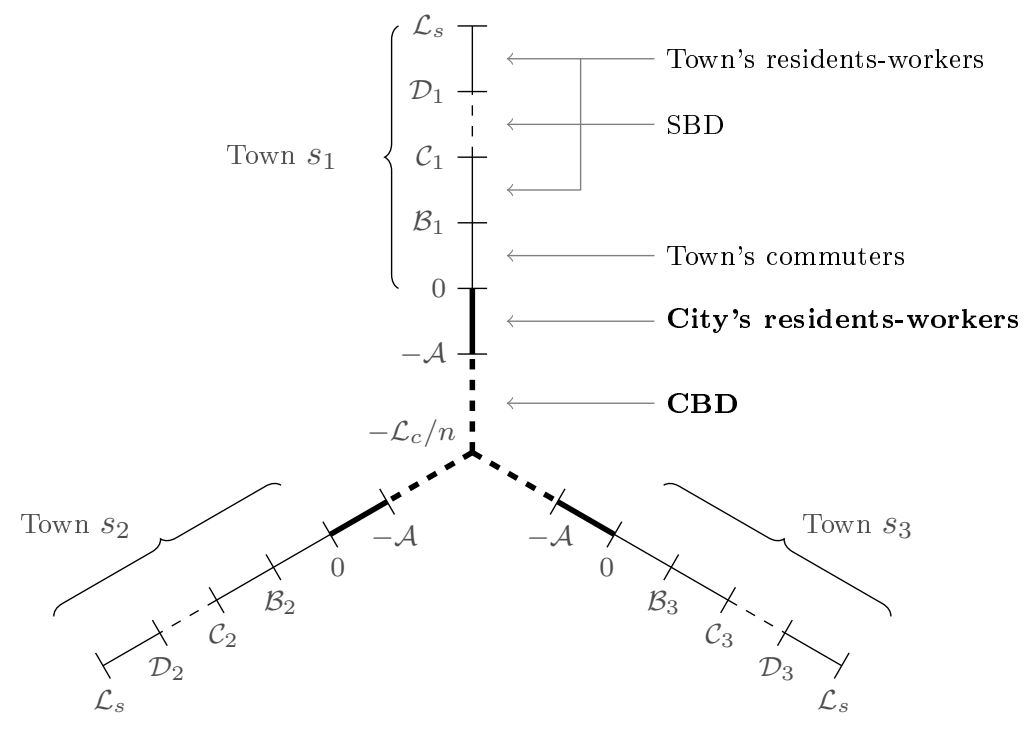

Figure 1. Graphical representation of the MA, with $n=3$.

For convenience, the spatial structure of the MA is depcited in Figure 1. The MA is composed of $n$ strips of 1 space unit width and $\mathcal{L}_{c} / n+\mathcal{L}_{s}$ space unit length. Thus, the total area of the MA is $\mathcal{L}_{c}+n \mathcal{L}_{s}$ that is, the sum of the land endowments of the city and the $n$ towns. Each strip is an interval $\left[-\mathcal{L}_{c} / n, \mathcal{L}_{s}\right]$ which links the center of the city, $-\mathcal{L}_{c} / n$, to the

${ }^{19}$ For instance, in 2016, among the 100 most populated French MAs, the central city accounted for $51 \%$ of the MA's workforce on average; $87 \%$ of cities accounted for more than a third of their MA workforces. Source: data collected from the French National Institute of Statistics and Economic Studies.

${ }^{20}$ Gaigné et al. (2016) make a related assumption. They assume that more than a third of the MA's population is concentrated in the city. Our assumption is less demanding since central cities usually employ a higher number of workers than their number of residents. 
extremity of one of the $n$ towns, $\mathcal{L}_{s}$. The city is represented spatially by the union of the $n$ intervals $\left[-\mathcal{L}_{c} / n, 0\right]$. Each of these intervals is divided between business land $\left[-\mathcal{L}_{c} / n,-\mathcal{A}\right]$ and residential land $[-\mathcal{A}, 0]$. Since each household consumes one unit of land, we have: ${ }^{21}$

$$
\mathcal{A} \equiv \frac{R_{c}}{n}
$$

The CBD is the union of the intervals $\left[-\mathcal{L}_{c} / n,-\mathcal{A}\right]$. It represents the business land used by firms located in the city whose total area is $L_{c}=\mathcal{L}_{c}-R_{c}$.

Each town is represented spatially by the interval $\left.] 0, \mathcal{L}_{s}\right]$. For each town $s_{i}$, this interval is divided into four subintervals:

- $\left.] 0, \mathcal{B}_{i}\right]$ of length $W_{s_{i} c}$, is occupied by the residents of $s_{i}$ who commute to the CBD.

- $\left.] \mathcal{B}_{i}, \mathcal{C}_{i}\right]($ resp. $\left.\left.] \mathcal{D}_{i}, \mathcal{L}_{s}\right]\right)$ of length $W_{s_{i} s_{i}} / 2$, is occupied by half of the residents of $s_{i}$ who work in $s_{i}{ }^{22}$

- $\left.] \mathcal{C}_{i}, \mathcal{D}_{i}\right]$ of length $L_{s_{i}}$, is the SBD of $s_{i}$.

Using (1) and (2), the following explicit expressions for $\mathcal{B}_{i}, \mathcal{C}_{i}$ and $\mathcal{D}_{i}$ result:

$$
\begin{aligned}
\mathcal{B}_{i} & \equiv W_{s_{i} c}=R_{s_{i}}-W_{s_{i}} \\
\mathcal{C}_{i} & \equiv W_{s_{i} c}+\frac{W_{s_{i} s_{i}}}{2}=R_{s_{i}}-\frac{W_{s_{i}}}{2} \\
\mathcal{D}_{i} & \equiv W_{s_{i} c}+\frac{W_{s_{i} s_{i}}}{2}+L_{s_{i}}=\mathcal{L}_{s}-\frac{W_{s_{i}}}{2}
\end{aligned}
$$

Next, we introduce commuting costs. An individual who lives at location $l$ and works at location $l^{\prime}$ incurs commuting cost: ${ }^{23}$

${ }^{21}$ Notice that $\mathcal{A}$ does not depend on $i$ which means that the amount of business land used by firms is the same on each strip of the MA. This is because the firms in the SBD pay the same land rent per business land unit regardless of which strip they are located on (see subsection 3.3).

${ }^{22}$ At equlibrium, there are only two possible locations for the SBD: (i) central to the distribution of the town's residents-workers; (ii) at the extremity of the town. We assume that the former case holds, e.g. for historical reasons. Gaigné et al. (2016) argue that a central location would be the optimal choice for the municipalities. Our results would be qualitatively similar with SBDs at the extremity of towns.

${ }^{23}$ This modeling of commuting costs with traffic congestion is in line with Fujita (1989). For tractability, we assume that $\mathbf{c}(l)$ is linear, and that the marginal congestion costs are same in the city and in the suburbs. The linerarity of our traffic congestion function is consistent with structural models of traffic congestion (Arnott et al., 1993). All the results derived in the paper can easily be generalized to any non-linear function of the form:

$$
T\left(l, l^{\prime}\right) \equiv\left\{\begin{array}{ll}
\widetilde{T}\left(l^{\prime}-l\right)+\int_{l}^{l^{\prime}} \mathbf{c}\left(z-W_{l^{\prime}}^{+}\right) \mathrm{d} z & \text { if } l<l^{\prime}, \\
\widetilde{T}\left(l-l^{\prime}\right)+\int_{l^{\prime}}^{l} \mathbf{c}\left(W_{l^{\prime}}^{+}-z\right) \mathrm{d} z & \text { if } l>l^{\prime},
\end{array} \quad \text { with } \mathbf{c}(z) \equiv a z^{b},\right.
$$

for any differentiable function $\widetilde{T}(\cdot)$ and scalars $a$ and $b$. 


$$
T\left(l, l^{\prime}\right) \equiv\left\{\begin{array}{ll}
\int_{l}^{l^{\prime}} \mathbf{c}\left(z-W_{l^{\prime}}^{+}\right) \mathrm{d} z & \text { if } l<l^{\prime}, \\
\int_{l^{\prime}}^{l} \mathbf{c}\left(W_{l^{\prime}}^{+}-z\right) \mathrm{d} z & \text { if } l>l^{\prime},
\end{array} \quad \text { with } \quad \mathbf{c}(z) \equiv t+a z\right.
$$

where $W_{l^{\prime}}^{+}$is the residence location of the individual working at $l^{\prime}$ living the farthest from $l^{\prime}$. $\mathbf{c}(l)$ is the marginal transportation cost at location $l$. Parameter $a>0$ (resp. $t>0$ ) captures traffic congestion costs (resp. distance costs), as explained below. We assume that workers incur no commuting costs within business districts: for example, an individual working in the CBD pays only for commuting from her residence location to the boundary of the CBD, $-\mathcal{A} .^{24}$

To understand commuting costs (7), consider an individual working in the $\mathrm{CBD}$, that is at location $l^{\prime}=-\mathcal{A}$, and living at location $\left.\left.l \in\right]-\mathcal{A}, \mathcal{B}_{i}\right]$ on one of the strips depicted in Figure 1 . The individual's commuting costs (7) can be written as:

$$
T(l,-\mathcal{A})=t(l+\mathcal{A})+a \int_{-\mathcal{A}}^{l}\left(\mathcal{B}_{i}-z\right) \mathrm{d} z
$$

The first part of $(8), t(l+\mathcal{A})$, is the traditional distance commuting costs considered in the literature (e.g. Braid, 2000; Peralta, 2007; Gaigné et al., 2016). Parameter $t$ is the cost per unit of distance. ${ }^{25}$ These costs (fuel, transport tickets, etc.) would be incurred by the commuter even were she the only individual on the road.

The second part of $(8), a \int_{-\mathcal{A}}^{l}\left(\mathcal{B}_{i}-z\right) \mathrm{d} z$, is the continuous sum of the traffic congestion costs that this individual incurs during the journey to work. At each location $l_{0}$, this commuter is on the road with $\mathcal{B}_{i}-l_{0}$ other commuters and pays the traffic congestion cost $a\left(\mathcal{B}_{i}-l_{0}\right)$.

Definition 1 (Traffic jam). Parameter $a>0$ is traffic jam intensity. It measures the marginal traffic congestion cost induced by an additional commuter.

The key parameter $a$ can be interpreted as the inverse of the transportation supply at each location $l$. Definition 1 highlights the first key externality in this paper. Traffic congestion is not novel in the UE literature (see e.g. Fujita, 1989); however, to our knowledge, there are no studies of such externalities in a context of competition among sub-central governments. The study of traffic congestion in a tax competition context is allowed by the spatial urban structure introduced in this model and by the identification of commuters as residents.

\footnotetext{
${ }^{24}$ This is similar to the assumption in Fujita (1989, chap. VII) and Zenou (2009, chap. VI). Equivalently, we could assume that workers have the same random commuting cost whenever they enter a business district.

${ }^{25}$ For simplicity, commuting costs are assumed to be monetary costs. This ignores time opportunity costs. We do not think that this alternative formulation would provide dramatically different results since agents are homogeneous and thus earn the same wage if working at the same place.
} 


\subsection{Households}

All households are identical and composed of a single individual. An individual living at location $l$ in municipality $j \in\left\{c ; s_{i}\right\}$ and working at $l^{\prime}$ in $j^{\prime} \in\left\{c ; s_{i}\right\}$ consumes $x_{j j^{\prime}}$ units of a private numeraire good, and one unit of land paying land rent $\rho_{i}(l)$, supplies inelastically one unit of labor in $j^{\prime}$ receiving wage $w_{j^{\prime}}$, pays the commuting costs $T\left(l, l^{\prime}\right)$ and the local residential head tax $\tau_{j}^{R}$.

Each household is endowed with $k \equiv \mathcal{K} / \mathcal{P}$ units of capital and $\ell_{j} \equiv \mathcal{L}_{j} / \mathcal{P}$ units of each municipality $j$ 's land: the MA's capital endowment $\mathcal{K}$ and each municipality $j$ 's land endowment $\mathcal{L}_{j}$ are evenly distributed among all the households in the MA. Since $k$ is invested in the municipality providing the highest return, the equilibrium capital return $r$ is identical in all municipalities. The landowner of $\ell_{j}$ supplies it to the household or the firm making the highest bid and pays the land tax $\tau_{j}^{\mathcal{L}} \ell_{j}$ to municipality $j .{ }^{26}$ The budget constraint of a household who lives at location $l$ in municipality $j$ and works at location $l^{\prime}$ in municipality $j^{\prime}$ is:

$$
x_{j j^{\prime}}+\rho_{i}(l)=w_{j^{\prime}}-T\left(l, l^{\prime}\right)-\tau_{j}^{R}+r k+\Gamma .
$$

where $\Gamma$ is the individual land income net of land taxation, whose explicit form can be found in Appendix A. This individual's utility is:

$$
x_{j j^{\prime}}+U^{j}\left(G_{j}\right)+U^{j j^{\prime}}\left(G_{j^{\prime}}\right) \equiv x_{j j^{\prime}}+U^{j}+U^{j j^{\prime}},
$$

where $G_{j}$ is the local public good provided by government $j$. The utility derived from public good consumption is increasing and concave, that is $U_{G}^{j}, U_{G}^{j j^{\prime}}>0$ and $U_{G G}^{j}, U_{G G}^{j j^{\prime}}<0$, where the subscripts denote derivatives.

Definition 2 (Commuting spillovers). Function $U^{j j^{\prime}}$ measures benefits earned by workers from local public services and amenities (safety, road conditions, etc.) provided at their workplace.

Function $U^{j j^{\prime}}$ captures utility spillovers in local public good consumption induced by commuting. Local authorities can make their municipality more attractive to workers by improving these services and amenities. ${ }^{27}$ Typically, a resident of town $s_{i}$ who considers commuting to the city compares the sub-utilities of working in her home town, $x_{s_{i} s_{i}}+U^{s_{i} s_{i}}\left(G_{s_{i}}\right)$, and working in the city, $x_{s_{i} c}+U^{s_{i} c}\left(G_{c}\right)$. Her decision depends not only on private consumption $x_{j j^{\prime}}$ but also on public good provision both in the city and in her residence town, captured by $U^{j j^{\prime}}$.

\footnotetext{
${ }^{26}$ The competition for land between households and firms is in line with that introduced in Ly (2018a).

${ }^{27}$ Local public goods limited to residents (e.g. local public schools) are not considered in the paper. Generalizing the paper results to such goods is straightforward.
} 
Definition 2 highlights the second key externality of this paper. To our knowledge, this model is the first to investigate local public good provision in the presence of commuting spillovers. This is enabled by the fact that each commuter is identified as a resident whereas in previous tax competition models commuters are pure private inputs, thus $U^{j j^{\prime}}=0$ (e.g. Braid, 1996, 2000; Peralta, 2007; Kächelein, 2014; Ly, 2018a).

The indirect utility of a household residing in $j$ at location $l$ and working in $j^{\prime}$ at location $l^{\prime}$ is:

$$
V^{j j^{\prime}}(l) \equiv w_{j^{\prime}}-\rho_{i}(l)-T\left(l, l^{\prime}\right)-\tau_{j}^{R}+r k+\Gamma+U^{j}+U^{j j^{\prime}},
$$

where $x_{j j^{\prime}}$ has been substituted in (10) using (9). Residential mobility implies that every resident in the MA obtains the same level of utility $u$ at equilibrium. Equating the indirect utility function (11) with the prevailing utility level $u$, and solving for $\rho_{i}(l)$ allows us to determine the residential bid land rent:

$$
\psi_{i}(l)=w_{j^{\prime}}-T\left(l, l^{\prime}\right)+\Lambda^{j j^{\prime}}-u
$$

where $\Lambda^{j j^{\prime}} \equiv r k+\Gamma+U^{j}+U^{j j^{\prime}}-\tau_{j}^{R}$, with $j, j^{\prime} \in\left\{c ; s_{i}\right\}$. The bid land rent $\psi_{i}(l)$ is the maximum rent that a household working in $j^{\prime}$ is willing to pay to live at location $l$.

The marginal resident of town $s_{i}$ who is indifferent between working in the CBD and working in the SBD of $s_{i}$ resides at location $l=\mathcal{B}_{i}$ which is characterized by:

$$
V^{s_{i} c}\left(\mathcal{B}_{i}\right)=V^{s_{i} s_{i}}\left(\mathcal{B}_{i}\right)
$$

\subsection{Firms}

In municipality $j \in\left\{c ; s_{i}\right\}$, the private good is produced combining labor $W_{j}$, capital $K_{j}$ and business land $L_{j}$ according to the production function $F^{j} \equiv F^{j}\left(W_{j}, K_{j}, L_{j}\right)$ which represents all local firms in municipality $j . F^{j}$ exhibits constant returns to scale and satisfies $F_{X}^{j}>0$, $F_{X X}^{j}<0$ and $F_{X Y}^{j}>0$ for all $X, Y \in\left\{K_{j} ; W_{j} ; L_{j}\right\}$, which means that $F^{j}$ exhibits positive but decreasing marginal returns with respect to each factor, and that factors are technological complements. $^{28}$ The profit of the firms in municipality $j$ is:

$$
\Pi^{j} \equiv F^{j}\left(W_{j}, K_{j}, L_{j}\right)-\left(w_{j}+\tau_{j}^{W}\right) W_{j}-\left(r+\tau_{j}^{K}\right) K_{j}-\rho_{j}^{L} L_{j}
$$

\footnotetext{
${ }^{28}$ Our main results hold whenever $F^{j}$ is homogeneous whatever its degree of homogeneity. Increasing returns to scale - often interpreted as agglomeration economies (Burbidge and Cuff, 2005) — were included in a preliminary version of this model (see Ly, 2018b). However, constant returns to scale do not rule out agglomeration economies. They can be included by assuming that factors are more productive in the city than in towns, that is $\forall(W, K, L), F^{c}(W, K, L)>F^{s}(W, K, L)$, as assumed in the numerical example of section 5 .
} 
where $w_{j}$ is the wage prevailing in municipality $j, r$ is the MA return to capital, $\rho_{j}^{L}$ is the municipal business land rent, $\tau_{j}^{W}$ is the tax rate on labor levied by municipality $j{ }^{29}$ and $\tau_{j}^{K}$ is its capital tax rate. For each municipality $j \in\left\{c ; s_{i}\right\}$, optimal demand for labor $W_{j}$ and capital $K_{j}$ maximize $\Pi^{j}$ and are characterized by:

$$
\begin{aligned}
& F_{W}^{j}=w_{j}+\tau_{j}^{W}, \\
& F_{K}^{j}=r+\tau_{j}^{K},
\end{aligned}
$$

where $F^{j}$ 's subscripts stand for derivatives. Firms make no profit at equilibrium, so that for each municipality $j \in\left\{c ; s_{i}\right\}, \Pi^{j}=0$. Solving the zero-profit condition for $\rho_{j}^{L}$ determines the business bid land rent:

$$
\psi_{j}^{L}=F_{L}^{j}
$$

which is obtained by inserting (15), (16) and Euler's identity $F^{j}=F_{W}^{j} W_{j}+F_{K}^{j} K_{j}+F_{L}^{j} L_{j}$ into the zero-profit condition. The bid land rent $\psi_{j}^{L}$ is the maximum rent that firms are ready to pay for land $L_{j}$. Firms compete with households for land which implies that in each municipality, the business bid land rent is equal to the residential bid land rent offered by the resident who lives the closest to the business district: ${ }^{30}$

$$
\psi_{c}^{L}=\psi_{i}(-\mathcal{A}), \quad \psi_{s_{i}}^{L}=\psi_{i}\left(\mathcal{C}_{i}\right)=\psi_{i}\left(\mathcal{D}_{i}\right)
$$

Eliminating $\psi_{i}(l), l \in\left\{-\mathcal{A} ; \mathcal{C}_{i} ; \mathcal{D}_{i}\right\}$ using (12) and $\psi_{j}^{L}$ using (17) from (18), for each municipality $j \in\left\{c ; s_{i}\right\}$ we obtain:

$$
F_{L}^{j}=w_{j}+\Lambda^{j j}-u
$$

recalling that the individual residing at locations $-\mathcal{A}, \mathcal{C}$ and $\mathcal{D}$ pay no commuting costs. Condition (19) characterizes the distribution of land between residents and firms in municipality $j$.

\subsection{Location system}

The previous subsections described the behavior of individual households and firms. At the metropolitan level, these decentralized behaviors entail a specific distribution of capital, residents and workers among municipalities. This subsection characterizes this distribution by deriving the so-called location system which is of particular importance to local governments.

${ }^{29}$ Notice that assuming alternatively that $\tau_{j}^{W}$ is paid directly by workers would lead to strictly identical results. However, it is simpler from a modeling viewpoint, to introduce $\tau_{j}^{W}$ in firms' profit.

${ }^{30}$ Suppose for instance that firms in town $s_{i}$ bid more than residents at $l=\mathcal{C}_{i}$, so that $\psi_{s_{i}}^{L}>\psi_{i}\left(\mathcal{C}_{i}\right)$. In this case, some owners of residential land decide to supply their land to firms, business land increases in $s_{i}$ and firms bid less for land (since $F_{L L}^{s_{i}}<0$ ) until $\psi_{s_{i}}^{L}=\psi_{i}\left(\mathcal{C}_{i}\right)$. 
Since the return to capital $r$ is the same throughout the MA, $r$ can be eliminated from the condition for capital input demand (16) so that:

$$
F_{K}^{c}-\tau_{c}^{K}=F_{K}^{s_{i}}-\tau_{s_{i}}^{K}
$$

Conditions (e.1) and (e.4) characterize the distribution of capital $\left\{K_{c} ; K_{s_{1}} ; \ldots ; K_{s_{n}}\right\}$ in the MA. Similarly, the same utility level $u$ prevails throughout the MA, so that $u$ can be eliminated from the marginal renter condition (19):

$$
F_{W}^{c}-\tau_{c}^{W}-F_{L}^{c}+U^{c}+U^{c c}-\tau_{c}^{R}=F_{W}^{s_{i}}-\tau_{s_{i}}^{W}-F_{L}^{s_{i}}+U^{s_{i}}+U^{s_{i} s_{i}}-\tau_{s_{i}}^{R}
$$

where the definition of $\Lambda^{j j}$ and the optimal condition for labor and land input demand, (15) and (17), have been inserted. Conditions (e.2) and (e.5) characterize the distribution of residents $\left\{R_{c} ; R_{s_{1}} ; \ldots ; R_{s_{n}}\right\}$ in the MA. The marginal worker condition (13) can be written explicitly as:

$$
F_{W}^{c}-\tau_{c}^{W}+U^{s_{i} c}-T(\mathcal{B},-\mathcal{A})=F_{W}^{s_{i}}-\tau_{s_{i}}^{W}+U^{s_{i} s_{i}}-T(\mathcal{B}, \mathcal{C})
$$

using the expression for the indirect utility (11) and replacing the wages from the optimal condition for labor input demand (15). Conditions (e.3) and (e.6) characterize the distribution of labor $\left\{W_{c} ; W_{s_{1}} ; \ldots ; W_{s_{n}}\right\}$ in the MA.

In sum, the $(3 n+3)$-equation location system (e.1)-(e.6) - in which $L_{j}, j \in\left\{c ; s_{i}\right\}$ has been substituted in the production function using (2) - implicitly defines the $3 n+3$ variables $\left\{K_{j} ; R_{j} ; W_{j}\right\}_{j \in\left\{c ; s_{i}\right\}}$ as a function of the local governments' policy instruments $\left\{G_{j} ; \tau_{j}^{K} ; \tau_{j}^{R} ; \tau_{j}^{W} ; \tau_{j}^{\mathcal{L}}\right\}_{j \in\left\{c ; s_{i}\right\}}$. As will be seen in the next section, the location pattern characterized by system (e.1)-(e.6) is the main driving force behind municipality's policies.

\section{Decentralized policies}

Pareto efficiency is characterized in the online appendix . In this section, we characterize decentralized local public policies chosen by municipalities when local labor taxation/subsidy is allowed (subsection 4.1) and when it is proscribed (subsection 4.2). Since all towns $s_{i}$ are identical, we drop index $i$ in the remainder of the paper.

\subsection{Optimal local public policies with labor taxes/subsidies: First-best}

This subsection considers the case where local labor taxes/subsidies $\tau_{j}^{W}, j \in\{c ; s\}$ are available so that each local government $j \in\{c ; s\}$ finances its local public good provision $G_{j}$ by levying a head tax on its residents $\tau_{j}^{R}$, a unit tax on capital $\tau_{j}^{K}$, a unit tax on labor $\tau_{j}^{W}$ and a unit 
tax on land property $\tau_{j}^{\mathcal{L}}$. Local government $j$ 's budget constraint is:

$$
\tau_{j}^{R} R_{j}+\tau_{j}^{K} K_{j}+\tau_{j}^{W} W_{j}+\tau_{j}^{\mathcal{L}} \mathcal{L}_{j}=C^{j}
$$

where $C^{j} \equiv C^{j}\left(G_{j}\right)$ is the increasing cost function of public good provision, so that $C^{j \prime}\left(G_{j}\right) \equiv C_{G}^{j}>0 .{ }^{31}$ Municipality $j$ chooses freely $\tau_{j}^{R}, \tau_{j}^{K}, \tau_{j}^{W}$ and $G_{j}$, and adjusts the land tax $\tau_{j}^{\mathcal{L}}$ to clear its local budget constraint (20). ${ }^{32}$ Local government $j$ maximizes the utility of its residents. Residential mobility in $j$ implies that all residents of $j$ have the same equilibrium utility level. Then, government $j$ 's objective is reduced to maximizing the utility of a representative resident, say the resident living the closest to municipality $j$ 's business district that is, at $l=-\mathcal{A}$ for the city and at $l=\mathcal{C}$ or $l=\mathcal{D}$ for a town.

When making its policy choices, government $j$ considers as given the choices of the other governments. Additionally, government $j$ does not directly control for the location of capital, residents and workers, but it rationally takes into account their location responses to its policies. Due to their size difference (Assumption 1) city and towns do not account for the same set of location responses.

Since town $s$ is atomistic, it regards its decisions as having no effect on the variables in the city and the other towns. It accounts for the fact that its population $R_{s}$, workforce $W_{s}$ and capital $K_{s}$ are defined implicitly as functions of its policy instruments $\left\{\tau_{s}^{R} ; \tau_{s}^{K} ; \tau_{s}^{W} ; G_{s}\right\}$ by the location system (e.4), (e.5) and (e.6). Therefore, government $s$ 's problem is to maximize $V^{s s}(\mathcal{C})$, choosing $\tau_{s}^{R}, \tau_{s}^{K}, \tau_{s}^{W}$ and $G_{s}$, and subject to the location system (e.4)-(e.6). Unlike the towns, the size of the city is significant; the city accounts for the responses of all economic agents in the MA to its policy decisions. It accounts for the fact that the city's and the towns' population $\left(R_{c}\right.$ and $\left.R_{s}\right)$, workforce $\left(W_{c}\right.$ and $\left.W_{s}\right)$ and capital $\left(K_{c}\right.$ and $\left.K_{s}\right)$ are defined implicitly as functions of its policy instruments $\left\{\tau_{c}^{R} ; \tau_{c}^{K} ; \tau_{c}^{W} ; G_{c}\right\}$ by the location system (e.1)(e.6). Government $c^{\prime}$ s problem therefore, is to maximize $V^{c c}(-\mathcal{A})$, choosing $\tau_{c}^{R}, \tau_{c}^{K}, \tau_{c}^{W}$ and $G_{c}$, subject to the full location system (e.1)-(e.6).

Solving the municipalities' maximization problems, the following result can be derived:

Result 1. The optimal public policy rules followed by the benevolent local government of municipality $j \in\{c ; s\}$ when financing its public good provision $G_{j}$ using the tax instrument

\footnotetext{
${ }^{31}$ For simplicity, we consider nonrival public goods, while most empirical studies find evidence of rivalry (e.g. Bergstrom and Goodman, 1973). See Ly (2018b) for a version of the model with this rival public goods; the results are in line with those in this paper.

${ }^{32}$ Formally, $\tau_{j}^{\mathcal{L}}$ is eliminated from the net land income $\Gamma$ using $(20)$ in the remainder of the paper (see Appendix A.2). Note that whatever the other instrument (i.e. $\tau_{j}^{R}, \tau_{j}^{K}, \tau_{j}^{W}$ or $G_{j}$ ) the modeler chooses to account for budget constraint $(20)$, the results would be unchanged: $\tau_{j}^{\mathcal{L}}$ would still be used indirectly as the budgetclearing instrument by municipalities since $\mathcal{L}_{j}$ is fix, contrary to $R_{j}, K_{j}, W_{j}$.
} 
$\operatorname{set}\left\{\tau_{j}^{R} ; \tau_{j}^{K} ; \tau_{j}^{W} ; \tau_{j}^{\mathcal{L}}\right\}$ are:

$$
\begin{array}{lll}
\tau_{s}^{W}=-\Phi, & (21 \mathrm{a}) & \tau_{c}^{W}=0, \\
\tau_{s}^{R}=t \frac{W_{s}}{2}+a\left(\frac{W_{s}}{2}\right)^{2}+\Phi, & (22 \mathrm{a}) & \tau_{c}^{R}=t \frac{W_{c}}{n}+a\left(\frac{W_{c}}{n}\right)^{2}, \\
\tau_{s}^{K}=0, & (23 \mathrm{a}) & \tau_{c}^{K}=0, \\
R_{s} U_{G}^{s}+W_{s} U_{G}^{s s}=C_{G}^{s}, & (24 \mathrm{a}) & R_{c}\left(U_{G}^{c}+U_{G}^{c c}\right)+n W_{s c} U_{G}^{s c}=C_{G}^{c},
\end{array}
$$

where $\tau_{j}^{\mathcal{L}}, j \in\{c ; s\}$ allows to clear the budget constraint (20). And:

$$
\Phi \equiv \frac{a}{2}\left[\left(\frac{W_{c}}{n}\right)^{2}-\left(\frac{W_{s}}{2}\right)^{2}\right]>0 .
$$

whose positive sign stems from Assumption 2.

Proof. See Appendix B.

Result 1 implies that:

Corollary 1. The decentralized equilibrium levels of $\tau_{c}^{R}-\tau_{s}^{R}, \tau_{c}^{K}-\tau_{s}^{K}, R_{s}, K_{s}$ and $W_{s}$, when the local tax instrument set is $\left\{\tau_{j}^{W} ; \tau_{j}^{R} ; \tau_{j}^{K} ; \tau_{j}^{\mathcal{L}}\right\}, j \in\{c ; s\}$ are characterized by:

$$
\begin{aligned}
& \tau_{c}^{W}-\tau_{s}^{W}=\Phi \\
& \tau_{c}^{R}-\tau_{s}^{R}=t\left(\frac{W_{c}}{n}-\frac{W_{s}}{2}\right)+\Phi \\
& \tau_{c}^{K}-\tau_{s}^{K}=0 \\
& x_{c c}+F_{L}^{c}=x_{s c}+F_{L}^{s} \\
& F_{K}^{c}=F_{K}^{s} \\
& F_{W}^{c}-x_{s c}-t \frac{W_{c}}{n}-a\left(\frac{W_{c}}{n}\right)^{2}=F_{W}^{s}-x_{s s}-t \frac{W_{s}}{2}-a\left(\frac{W_{s}}{2}\right)^{2} .
\end{aligned}
$$

and $R_{c}, K_{c}$ and $W_{c}$ are defined by the constraints (e.1)-(e.3).

Proof. See the online appendix .

Corollary 1 reveals that municipalities choose their policy instruments in accordance with a central planner's efficiency rules. ${ }^{33}$ Competing local governments which can finance local

${ }^{33}$ Conditions (24a), (24b) and (26)-(31) are strictly equivalent to the efficiency conditions (OA.5)-(OA.12) 
public goods $G_{j}$ using the tax instrument set $\left\{\tau_{j}^{R} ; \tau_{j}^{K} ; \tau_{j}^{W} ; \tau_{j}^{\mathcal{L}}\right\}$ are provided indirectly with incentives to implement the efficient allocation of resources in the MA.

$\star$ Labor taxation. Conditions (21a) and (21b) characterize the setting of local labor taxes. Condition (21a) indicates that town $s$ uses its labor tax as a subsidy. The rationale behind this central result is as follows. Given the population $R_{s}$, an additional worker in the SBD of $s$ is a resident of $s$ who initially was commuting to the CBD. This can be depicted as a one unit shift of point $\mathcal{B}_{i}$ towards 0 in Figure 1 . Then, the total traffic congestion cost decreases by $0.5 a\left(W_{c} / n\right)^{2}$ - in the city, and increases - by $0.5 a\left(W_{s} / 2\right)^{2}$ - in a town. Assumption 2, implies that due to the high concentration of workers in the CBD $\left(W_{c} / n>W_{s} / 2\right)$, the additional worker in the SBD of $s$ reduces the net traffic congestion cost incurred by the residents of $s$. This gain is internalized by government $s$ by a labor subsidy as stated in (21a).

Intuitively, condition (21a) means that since traffic congestion is higher in the city than in the suburbs, the town governments subsidize their workers to prevent to many from commuting to the CBD. Importantly, if there were no traffic congestion $(a=0)$, towns would have no incentive to use the labor subsidy (i.e. $\tau_{s}^{W}=0$, since $\Phi=0$ ). Traffic congestion requires that the towns' tax instrument sets include local labor taxes to achieve a Pareto efficient allocation of labor in the MA.

According to condition (21b), the city does not use its labor tax. This indicates that the efforts made by the self-interested atomistic towns to retain their workers are sufficient to ensure an optimal level of traffic congestion in the city.

$\star$ Residential taxation. Conditions (22a) and (22b) characterize the residential taxation rules. Condition (22b) indicates that the fiscal benefit $\tau_{c}^{R}$ of a new resident in $c$ covers the additional cost of commuting to the CBD induced by this new resident: $t W_{c} / n+a\left(W_{c} / n\right)^{2}$. By crowding out one unit of business land (shift of $-\mathcal{A}$ towards $\mathcal{L}_{c} / n$ in Figure 1 ), the new resident increases the overall distance to the CBD by $W_{c} / n .^{34}$ This implies an additional commuting cost of $t W_{c} / n$ due to distance and $a\left(W_{c} / n\right)^{2}$ due to traffic congestion.

Intuitively, a new resident in $c$ makes the CBD less accessible by increasing the cost of commuting to work in $c$. In order to safeguard an optimal level of access to the CBD, local government $c$ uses its residential tax $\tau_{c}^{R}$ to control its population size. ${ }^{35}$

characterized in the online appendix . The economic interpretations of conditions (26)-(31) can be found in the online appendix .

${ }^{34}$ Each of the $W_{c} / n$ CBD workers located on the strip on which the new resident settles incurs one more space unit of commuting.

${ }^{35}$ Notice that if commuting is not costly that is $t=a=0$, local governments do not use their tax on residents. In this case, local authorities know that workers are perfectly mobile so that a jurisdiction's population and workforce are not connected directly. $\tau^{R}$ cannot be used to control access to the business district. 
Like condition (22b), condition (22a) indicates that the residential tax $\tau_{s}^{R}$ internalizes the additional congestion cost induced by a new resident: $t W_{s} / 2+a\left(W_{s} / 2\right)^{2}$. Indeed, a new resident living and working in $s$ crowds out one unit of business land and increases the commuting distance to the SBD of $s$ by $W_{s} / 2$ space units which generates the additional commuting costs mentioned above. ${ }^{36,37}$ Compared to the city, an additional cost is internalized by the residential tax in town $s$. This cost is the subsidy $-\tau_{s}^{W}=\Phi$ offered to the new residentworker settling in $s$, according to condition (21a).

* Capital taxation. Conditions (23a) and (23b) which characterize the capital taxation rules, state, as standard, that municipalities have no incentive to tax capital. Capital entails no externality to be internalized.

* Public good provision. Conditions (24a) and (24b) characterize the public good provision rules. They are Samuelson efficiency rules extended to an economy in which mobile workers also benefit from local public goods. They state that municipality $j \in\{c ; s\}$ chooses its public good provision $G_{j}$ so as to equalize the sum of the marginal willingness to pay for its public good to the marginal cost of providing the public good, $C_{G}^{j}$.

Condition (24a) indicates that town $s$ accounts for the satisfaction of all its residents $R_{s} U_{G}^{s}$ and especially its residents-workers $W_{s} U_{G}^{s s}$. Interestingly, condition (24b) reveals that the city not only accounts for the benefits of its own residents $R_{c}\left(U_{G}^{c}+U_{G}^{c c}\right)$ but also internalizes the public good spillovers induced by workers' mobility from the suburb to the city $n W_{s c} U_{G}^{s c} \cdot{ }^{38}$

The main result of this subsection can be summarized in the following proposition:

Proposition 1. If local labor taxation/subsidy is allowed, a decentralized equilibrium leads to Pareto-efficiency, and:

(i) towns subsidize labor to internalize the traffic jam cost differential with the city.

(ii) residential taxation guarantees optimal access to business districts.

(iii) capital taxation is not used.

(iv) public good provision follows the Samuelson rule extended to commuting spillover.

\footnotetext{
${ }^{36}$ We assume in this interpretation that the new resident works in the SBD. We could also transform (22a) using (e.6) to describe the case of a new resident commuting to the CBD. The resulting condition is less easy to interpret even if the same forces are at stake.

${ }^{37}$ Contrary to $\tau_{j}^{R}, \tau_{j}^{W}$ does not internalize the commuting cost due to distance $t W_{j}^{+}$, where $W_{j}^{+}$is as defined in (7). The reason for this is that given the number of workers, new residents increase the overall commuting distance in $j$ by crowding out business land. However, given the number of residents, new workers do not affect the overall commuting distance in $j$.

38 This result echoes Tiebout's (1956) result. Here, residential mobility forces the city to account for all household welfare when providing its public good. Wellisch (1993) derives a similar results in a regional tax competition model.
} 
Proposition 1 presents an original picture of local government behavior compared to the LPE literature which is further discussed in section 6.

\subsection{Optimal local public policies absent labor taxes/subsidies}

The above analysis assumes that the local tax instrument set includes labor taxation/subsidy. Therefore, towns are able to internalize traffic congestion by using labor subsidies as a Pigouvian policy instrument. However, in OECD countries labor subsidies are rarely available at the local level (section 1). We now consider the more common case where municipalities have no access to local labor taxes/subsidies. Solving the same municipality maximization problems as in subsection 4.1 , with $\tau_{j}^{W}=0$, the following result can be derived:

Result 2. The optimal public policy rules followed by the benevolent local government of municipality $j \in\{c ; s\}$ when financing its public good provision $G_{j}$ using the tax instrument set $\left\{\tau_{j}^{R} ; \tau_{j}^{K} ; \tau_{j}^{\mathcal{L}}\right\}$ are:

$$
\begin{array}{lll}
\tau_{s}^{R}=t \frac{W_{s}}{2}+a\left(\frac{W_{s}}{2}\right)^{2}+\Phi+d_{s}^{R}, & (32 \mathrm{a}) & \tau_{c}^{R}=t \frac{W_{c}}{n}+a\left(\frac{W_{c}}{n}\right)^{2}+d_{s}^{R}-d_{c}^{R} \\
\tau_{s}^{K}=-d_{s}^{K}, & (33 \mathrm{a}) & \tau_{c}^{K}=-d_{s}^{K}+d_{c}^{K} \\
R_{s} U_{G}^{s}+W_{s} U_{G}^{s s}=C_{G}^{s}-d_{s}^{G}, & (34 \mathrm{a}) & R_{c}\left(U_{G}^{c}+U_{G}^{c c}\right)+n W_{s c} U_{G}^{s c}=C_{G}^{c}+d_{c}^{G}
\end{array}
$$

and $\tau_{j}^{\mathcal{L}}$ clears the budget constraint (20) with $\tau_{j}^{W}=0$. The distortion terms are defined as: ${ }^{39}$

$$
\begin{aligned}
d_{s}^{R} \equiv\left(F_{W L}^{s}-t-a W_{c} / n\right) \frac{\Phi}{D_{s}}, & d_{s}^{K} \equiv F_{W K}^{s} \frac{\Phi}{D_{s}}>0, & d_{s}^{G} \equiv U_{G}^{s s} \frac{\Phi}{D_{s}}>0, \\
d_{c}^{R} \equiv\left(n F_{W L}^{c}+F_{W L}^{s}\right) \frac{\Phi}{D_{c}}>0, & d_{c}^{K} \equiv\left(n F_{W K}^{c}+F_{W K}^{s}\right) \frac{\Phi}{D_{c}}>0, & d_{c}^{G} \equiv n U_{G}^{s c} \frac{\Phi}{D_{c}}>0,
\end{aligned}
$$

where $\Phi$ is defined in (25) and $\Phi>0$ under Assumption 2, and:

$$
D_{s} \equiv \frac{3}{2} t+a\left(\frac{W_{c}}{n}+\frac{W_{s}}{4}\right)-F_{W W}^{s}>0, \quad D_{c} \equiv D_{s}-n F_{W W}^{c}>0 .
$$

Proof. See Appendix C.

Result 2 implies that:

\footnotetext{
${ }^{39}$ The signs are obtained recalling that $\Phi \geq 0, F_{X X}<0$ and $F_{X Y}>0$ for all $X, Y \in\{K ; W ; L\}$.
} 
Corollary 2. The decentralized equilibrium levels of $\tau_{c}^{R}-\tau_{s}^{R}, \tau_{c}^{K}-\tau_{s}^{K}, R_{s}, K_{s}$ and $W_{s}$, when the local tax instrument set is $\left\{\tau_{j}^{R} ; \tau_{j}^{K} ; \tau_{j}^{\mathcal{L}}\right\}, j \in\{c ; s\}$ are characterized by:

$$
\begin{aligned}
& \tau_{c}^{R}-\tau_{s}^{R}=t\left(\frac{W_{c}}{n}-\frac{W_{s}}{2}\right)+\Phi+d_{c}^{R} \\
& \tau_{c}^{K}-\tau_{s}^{K}=d_{c}^{K} \\
& x_{c c}+F_{L}^{c}+d_{c}^{R}=x_{s c}+F_{L}^{s} \\
& F_{K}^{c}-d_{c}^{K}=F_{K}^{s} \\
& F_{W}^{c}-x_{s c}-t \frac{W_{c}}{n}-a\left(\frac{W_{c}}{n}\right)^{2}+\Phi=F_{W}^{s}-x_{s s}-t \frac{W_{s}}{2}-a\left(\frac{W_{s}}{2}\right)^{2} .
\end{aligned}
$$

and $R_{c}, K_{c}$ and $W_{c}$ are defined by the constraints (e.1)-(e.3).

Proof. See the online appendix .

Comparing Corollary 2 to the Pareto-efficient outcome of Corollary 1 shows that municipality behaviors are distorted in a sub-efficient way, as shown by the distortion terms $d_{j}^{\mathrm{x}}, j=\{c ; s\}$ and $\mathrm{x} \in\{R ; K ; G\} .^{40}$ The only cause of these distortions is the impossibility for towns to regulate traffic congestion using labor subsidies. ${ }^{41}$ Since towns cannot subsidize workers, there are too many workers in the city and too few in the suburbs. This labor misallocation can be seen in the presence of $\Phi>0$ in condition (39) which was absent from efficiency condition (31). Then, town (resp. city) authorities distort their remaining instruments $\left\{\tau_{j}^{R} ; \tau_{j}^{K} ; G_{j}\right\}$ to be more (resp. less) attractive to workers.

$\star$ Residential taxation. Condition (32a) depicts how town $s$ distorts its tax on residents to overcome the absence of labor tax. The sign of the distortion $d_{s}^{R}$ is ambiguous. To understand this, consider two polar cases.

First, suppose that $t>0, a>0$ and $F_{W L}^{s} \approx 0$. Then, $d_{s}^{R}<0$ that is, the towns under-tax their residents compared to (22a). Imperfect worker mobility (i.e. costly commuting) spurs the towns to set a low residential tax to attract residents-workers and hence alleviate the traffic congestion incurred by their residents working in the CBD.

Second, suppose that $t \approx 0, a \approx 0$ and $F_{W L}^{s}>0$. Then, $d_{s}^{R}>0$ that is, the towns overtax their residents. Local authorities know that population and workforce are not linked by imperfect worker mobility since commuting is not costly. However, they can attract workers by increasing the amount of land available to firms. Indeed, technological complementarity

${ }^{40}$ See Figure OA.1 in the online appendix for an illustration of the misallocation implied by conditions (34a), (34b), and (37)-(39).

${ }^{41}$ Were there no traffic congestion, local governments would not distort their policy instruments. Indeed, $a=0$ implies $d_{j}^{\mathrm{x}}=0$, so that Result 2 and Corollary 2 become Result 1 and Corollary 1. 
$F_{W L}^{s}>0$ implies that more business land increases local wage and attracts workers. To increase the land size of their SBD, the towns over-tax residents to reduce their population and make room for business land.

The above two polar cases show that towns can under-tax or over-tax their residents, depending on the relative importance of commuting costs and technological complementarity between labor and business land.

Condition (32b), which characterizes the city's residential tax policy, can be better interpreted by considering condition (35) in which $d_{s}^{R}$ is eliminated using (32a). ${ }^{42}$ Comparing condition (35) to the first-best condition (27), indicates that given the towns' residential tax rate, the city chooses an inefficiently low residential tax rate, since $-d_{c}^{R}<0$.

This too low residential tax is a response to the excessive number of workers inducing traffic congestion in the city (condition (39)). The city cuts its residential tax to attract new residents, which limits the land size of the CBD and thus avoids some commuting flows. However, this attractive city residential tax policy entails a misallocation of residents in the MA. Condition (37) shows that the number of residents in the city (resp. towns) is inefficiently high (resp. low) compared to the Pareto-efficient condition (29).

* Capital taxation. Condition (33a), shows that the towns now subsidize capital, since $-d_{s}^{K}<0$. Compared to the first-best condition (23a), the towns now under-tax capital. Since they cannot subsidize labor, they subsidize capital to attract workers, exploiting the technological complementarity between capital and labor $\left(F_{W K}^{s}>0\right)$.

Condition (33b) indicates that the specific distortion of the city's capital tax is positive, $d_{c}^{K}>0$. This distortion can be better understood by comparing (36) to the first-best condition (28). ${ }^{43}$ Condition (36) shows that the city chooses an inefficiently high capital tax rate, given the towns' capital tax rate, since $d_{c}^{K}>0$.

In response to the excessive number of costly workers in the $\mathrm{CBD}$, the city authorities exploit the technological complementarity between capital and labor, by increasing their capital tax. By doing so, they discourage capital, and thus indirectly discourage workers from locating in the city. Condition (38) shows that the amount of capital in the city (resp. towns) is inefficiently low (resp. high) compared to the Pareto-efficient condition (30).

\footnotetext{
${ }^{42}$ Notice that the city's residential tax $\tau_{c}^{R}$ internalizes the distortion of the towns $d_{s}^{R}$, as can be seen in (32b). This is because residents' mobility links the welfare of city residents to the welfare of suburbanites; all households have the same level of utility at equilibrium.

${ }^{43}$ The city's capital tax $\tau_{c}^{K}$ internalizes the distortion of the towns $d_{s}^{K}$. The reason is the same as for $\tau_{c}^{R}$. See footnote 42 .
} 
* Public good provision. Condition (34a) shows that, since the towns cannot subsidize labor, the towns over-provide public goods compared to the efficient extended Samuelson rule (24a), since $-d_{s}^{G}<0$. By increasing their public good provision, the towns are able to encourage more workers to work in their SBD, since $U_{G}^{s s}>0$.

Condition (34b) indicates that the city behaves in an opposite way by providing an inefficiently low amount of public good, since $d_{c}^{G}>0$. Since towns cannot keep a sufficient number of workers, the city controls traffic congestion by decreasing its public good supply which discourages some suburbanites from commuting to the CBD, since $U_{G}^{s c}>0$.

The distortions in the local policy setting caused by the existence of traffic jams in the MA are summarized in the following proposition:

Proposition 2. If towns are not allowed to subsidize workers, a decentralized equilibrium does not lead to Pareto-efficiency, and under Assumption 2:

(i) the city under-taxes residents compared to the towns.

(ii) the city over-taxes capital compared to the towns.

(iii) the city (resp. towns) under-provides (resp. over-provide) local public goods.

Proposition 2, which shows the effects of traffic congestion on local public policy in a MA, is novel in the literature. The main new insight is the following. If the city concentrates an important share of the workforce of the MA (Assumption 2), the impossibility for towns to retain workers by employing subsidies entails an overflow of workers in the CBD. To prevent excess traffic congestion incurred by households working in the CBD, city and towns engage in inefficient policies. Notably, part (iii) indicates that local governments distort their public good provision accounting for local public good spillovers induced by commuting. The city (resp. towns) reduces (resp. increase) its (resp. their) public good provision to be less (resp. more) attractive to workers. To our knowledge, our model is the first to consider commuting spillovers and to depict how they can induce distortion in local governments' choices.

We have seen also that the distortions in the local policy setting induced by the excessive level of traffic congestion in the city relative to the towns (i.e. too many workers in the city) lead to a misallocation of residents and capital in the MA. This is summarized in the following proposition.

Proposition 3. If towns are not allowed to subsidize workers, under Assumption 2, a decentralized equilibrium leads to:

(i) an inefficiently high number of workers in the city, compared to the towns.

(ii) an inefficiently high number of residents in the city, compared to the towns. 
(iii) an inefficiently low amount of capital in the city, compared to the towns.

\section{Numerical example}

To gain general equilibrium insights into the results of section 4, this section provides a numerical illustration. The purpose is to shed a light on the distortions caused by various traffic jam intensities $a$. To this end, we assume that the cost function of public good provision is $C^{j}(G)=G^{2}$, that the utility function is $x_{j}+U^{j}\left(G_{j}\right)+U^{j j^{\prime}}\left(G_{j^{\prime}}\right)=x_{j}+G_{j}^{\gamma}+G_{j^{\prime}}^{\epsilon}$ and that the production is carried out by the Cobb-Douglas function $F^{j}\left(W_{j}, K_{j}, L_{j}\right)=A_{j} K_{j}^{\alpha} W_{j}^{\beta} L_{j}^{1-\alpha-\beta} \cdot{ }^{44}$

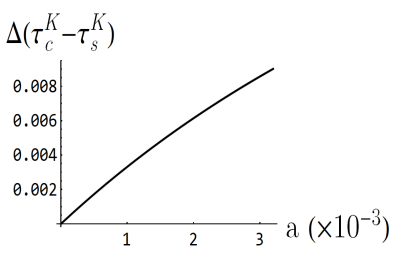

(a) Capital tax rate gap.

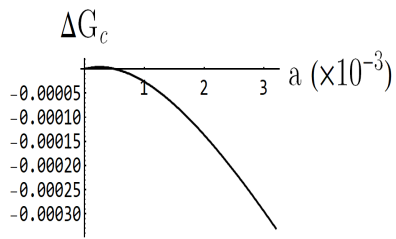

(c) Public good in the city.

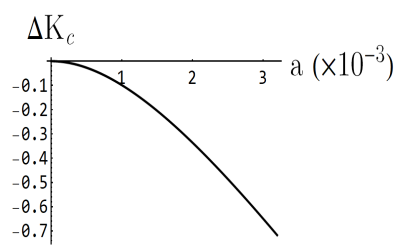

(e) Capital in the city.

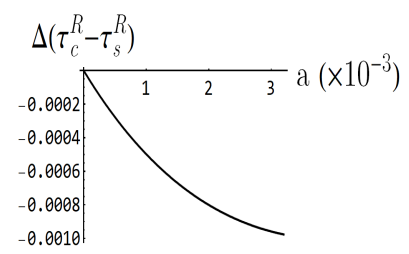

(b) Resident tax rate gap.

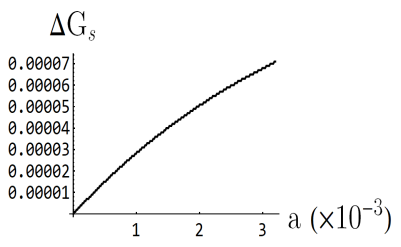

(d) Public good in town $s$.

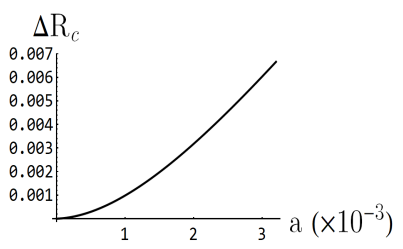

(f) Residents in the city.

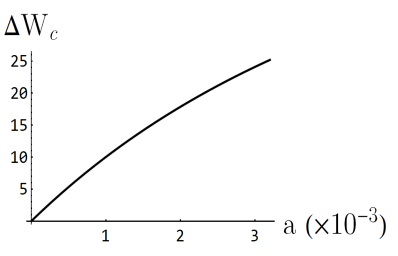

(g) Workers in the city.

Figure 2. Distortions with respect to traffic jam intensity $a$. For each variable $X, \Delta X \equiv X^{\star \star}-X^{\star}$ where $X^{\star}$ is the first-best (Pareto-efficient) equilibrium value of $X$ resulting from Result 1 , and $X^{\star \star}$ is its second-best equilibrium value resulting from Result 2.

Figure 2 reports the simulation results which depict the distortions of the key variables of the model as a function of traffic jam intensity $a$. The distortions $\Delta X$ with $X \in\left\{\tau_{c}^{K}-\tau_{s}^{K} ; \tau_{c}^{R}-\right.$

${ }^{44}$ The parameter values for the simulations are: number of towns, $n=650$; municipalities' land endowments, $\mathcal{L}_{c}=10000$ and $\mathcal{L}_{s}=300 ;$ MA's capital endowment and population, $\mathcal{K}=3000$ and $\mathcal{P}=5500$; elasticity of output w.r.t. capital and labor, $\alpha=0.55$ and $\beta=0.2$; elasticity of utility w.r.t. public good consumption at home and at work $\gamma=0.95$ and $\epsilon=0.01$; municipalities' productivity parameter $A_{c}=3$ and $A_{s}=1.5$. 
$\left.\tau_{s}^{R} ; G_{c} ; G_{s} ; K_{c} ; R_{c} ; W_{c}\right\}^{45}$ are measured as the difference between the equilibrium value of $X$ without local labor subsidies (Result 2 and Corollary 2) and the Pareto-efficient level of $X$ (Result 1 and Corollary 1).

The numeric results in Figure 2 are in line with Proposition 2 and Proposition 3. The simulations confirm that without traffic congestion $a=0$, Pareto-efficiency is achieved in the decentralized equilibrium without labor subsidy: $\Delta X=0$ for all variables. Figure $2 \mathrm{~g}$ indicates that an excessive number of workers in the CBD $\left(\Delta W_{c}>0\right)$ arises when there is traffic congestion $(a>0)$, and that this excess of workers gets worse as traffic congestion intensifies ( $a$ increases). Figures 2a-2d show how municipalities respond to the overcrowded CBD by increasingly distorting their policy instrument setting as $a$ increases.

First, Figure 2a indicates that the city sets a too high capital tax relative to the towns $\left(\Delta\left(\tau_{c}^{K}-\tau_{s}^{K}\right)>0\right)$. This strategy allows the city to reduce the size of the CBD by exerting excessive outflows of capital towards the towns, as illustrated by Figure 2e $\left(\Delta K_{c}<0\right)$.

Second, Figure $2 \mathrm{~b}$ highlights another way to cut the size of the CBD. The city sets an inefficiently low tax on residents compared to the towns $\left(\Delta\left(\tau_{c}^{R}-\tau_{s}^{R}\right)<0\right)$. This allows the city to attract a higher number of residents as suggested by Figure $2 \mathrm{f}\left(\Delta R_{c}>0\right)$, and to crowd out business land.

Finally, public good spillovers due to commuting allow municipalities to directly affect the workers flow. According to Figure 2c, to reduce its attractiveness to workers the city provides an inefficiently low amount of public good $\left(\Delta G_{c}<0\right)$. However, Figure $2 \mathrm{~d}$ shows that since towns want to retain their workers, they do the opposite and over-provide public goods $\left(\Delta G_{s}>0\right)$.

\section{Discussion}

The model developed in this paper sheds new light on several important and often longstanding LPE debates. This section discusses some of them. Subsection 6.1 highlights the original role played by residential taxation in MAs. Subsection 6.2 questions the standard result that cities charge higher tax rates than towns. Subsection 6.3 discusses how household mobility calls for a reconsideration of externalities at the local level. Subsection 6.4 outlines that labor taxation should not be regarded as a second-class policy in MAs.

\footnotetext{
${ }^{45}$ For space reasons, we do not report the graphs for $\Delta K_{s}=-\Delta K_{c} / n, \Delta R_{s}=-\Delta R_{c} / n$ and $\Delta W_{s}=-\Delta W_{c} / n$ which are symmetric to $\Delta K_{c}, \Delta R_{c}$ and $\Delta W_{c}$ with respect to the x-axis.
} 


\section{Discussion}

\subsection{A new role for the residential tax: job accessibility}

The paper sheds new light on the role of local residential taxes. In the literature, the essential motive for taxing mobile residents is to internalize crowding costs induced by their consumption of a rival local public good. This role has been confirmed for most types of residence based taxes such as head taxes (Wildasin, 1980, 1986), housing taxes (Hoyt, 1991; Krelove, 1993) and wage taxes (Wilson, 1995). ${ }^{46}$ In all these cases, without crowding costs, local governments do not tax their residents if they can finance public goods via another undistortive tax instrument.

In this paper, despite the nonrivalry of local public goods and the availability of an undistortive tax on land, municipalities use residential taxes - even without traffic congestion to control access to their business district: ${ }^{47}$ they raise their residential tax to discourage too many residents-workers from choosing their business district as a workplace. To our knowledge, the link between residential taxes and job accessibility has not previously been demonstrated.

\subsection{Who sets the highest tax rate in the $M A$ ?}

The paper also provides new insights into the longstanding question about which, city or towns, sets the highest taxes on capital and residents in a MA? The traditional tax competition literature is unambiguous: the city charges higher tax rates than the towns on both capital (Bucovetsky, 1991; Wilson, 1991; Bucovetsky, 2009) and residents (Epple and Zelenitz, 1981; Hoyt, 1992). ${ }^{48}$ The basic reason for this is that due to its larger population, a city has more influence on capital and housing prices than towns do, and therefore, can set higher tax rates on capital and housing.

These results have been confirmed by several theoretical contributions, especially for capital taxation. According to the new economic geography literature (e.g. Baldwin and Krugman, 2004), agglomeration economies lock mobile capital into the largest jurisdictions which benefit from this agglomeration rent and can levy a high capital tax rate on this quasi-fixed tax base. ${ }^{49}$ In a two-jurisdiction tax competition model with commuting, Kächelein (2014) shows that due to the limited geographic mobility of labor, the more populated jurisdiction sets a higher capital tax rate. Gaigné et al. (2016, p.108) find that the central city sets a higher

\footnotetext{
${ }^{46}$ The distortions arising when a residence-based tax is not available and local public goods are rivals are studied in Wellisch and Hulshorst (2000).

${ }^{47}$ Formally, this can be seen by assuming that $a=0$ and $t>0$ in (22a) and (22b).

${ }^{48}$ See Wilson (1999) and Brülhart et al. (2015) for surveys of the literature on asymmetric tax competition.

${ }^{49}$ Empirical evidence of the existence of taxable agglomeration rents is less clear. While Charlot and Paty (2007) for example provide results supporting this finding for French municipalities, Luthi and Schmidheiny (2013) using panel data of Swiss municipalities find no evidence of a positive impact of agglomeration forces on capital tax rates.
} 
business tax rate than suburban municipalities, due "to the central position of the CBD in the transportation network" (see subsection 6.4 below) ${ }^{50}$

Yet, the theoretical consensus stating that cities tax more heavily than towns does not always coincide with basic empirical facts. For instance, in 2009 among the ten most populated French MAs, $54 \%$ of suburban towns set a higher tax rate on capital than the rate set by the city in their MA, and $41 \%$ of towns set a higher housing tax rate (Ly, 2018b). ${ }^{51}$

This paper provides some insights which help to explain these observations. The model shows that whether the city or the towns set higher tax rates on capital and residents depends on the concentration of workers in the city. ${ }^{52}$ If the city concentrates a low share of the MA workforce, the city sets lower tax rates than the towns on both capital and residents. In other words, in MAs where jobs are not overly concentrated in the city, we should observe a more significant number of towns setting higher taxes on capital and residents than the city. The intuition is as follows. If the towns accounts for a high share of the workforce, then (i) the city taxes its capital less than the towns to reduce traffic congestion in the suburbs, and (ii) the city taxes its residents less than the towns to guarantee a sufficient level of access to jobs in SBDs.

\subsection{Externalities and household mobility}

Frequently, inter-jurisdictional externalities are considered as the main source of inefficiencies in a context of decentralized government activities. A local government, by accounting exclusively for the welfare of its own residents, ignores the benefits/costs of its policy choices for non-residents, and thus implements inefficient policies. This conclusion is based on the assumption of immobile residents which is not satisfactory in the case of sub-metropolitan jurisdictions such as municipalities. Residents' inter-jurisdictional mobility forces local governments to account for the welfare of non-residents such that at the local level, inter-jurisdictional externalities are minor. Our paper reveals that an important source of inefficiencies in MAs is the inter-individual externality of traffic congestion. This involves distortions which can

\footnotetext{
${ }^{50}$ A notable exception is Janeba and Osterloh (2013) where cities compete not only with the towns of their MA but also with cities in other MAs, while towns compete only with the municipalities in their particular MA. When the number of MAs is sufficiently large, the competition faced by a city is so high compared to that faced by the towns in its MA that the city sets a lower capital tax rate than that set by the towns.

${ }^{51}$ These mitigated results are noted by Brülhart et al. (2015, p. 1151): "empirical estimates provide conflicting evidence for the effect of population size on jurisdictions' tax rates."

${ }^{52}$ Formally, $\tau_{c}^{\mathrm{R}} \gtrless \tau_{s}^{\mathrm{R}}$ and $\tau_{c}^{\mathrm{K}} \gtrless \tau_{s}^{\mathrm{K}}$ if $W_{c} \gtrless \mathcal{P} / 3$. That is, the ordering of the tax rates depends on whether Assumption 2 holds or not. Proof. Algebraic manipulations show that condition (35) can be written as: $\tau_{c}^{R}-\tau_{s}^{R}=t\left(\frac{W_{c}}{n}-\frac{W_{s}}{2}\right)+\frac{\Phi}{D_{c}}\left(\frac{3 t}{2}+a\left(\frac{W_{c}}{n}+\frac{W_{s}}{4}\right)\right)$, so that $\operatorname{sign}\left(\tau_{c}^{R}-\tau_{s}^{R}\right)=\operatorname{sign}\left(W_{c} / n-W_{s} / 2\right)=\operatorname{sign}\left(W_{c}-\right.$ $\mathcal{P} / 3)$. From condition (36), we directly have $\operatorname{sign}\left(\tau_{c}^{K}-\tau_{s}^{K}\right)=\operatorname{sign}\left(W_{c}-\mathcal{P} / 3\right)$.
} 
work in the opposite direction to distortions induced by inter-jurisdictional externalities. This applies particularly to two types of externality.

The first is the fiscal externality induced by capital mobility. The standard tax competition result is that capital inter-jurisdictional mobility spurs local governments to set inefficiently low taxes on capital (Wilson, 1986; Zodrow and Mieszkowski, 1986). This inefficiency is due to a positive inter-jurisdictional externality: jurisdictions overlook the fact that increasing their own taxes will benefit other jurisdictions receiving capital inflows (Wildasin, 1989). Residential mobility eliminates this externality since "tax competition does not matter in the case of household mobility, since each region considers the welfare of nonresidents by taking the migration equilibrium into account" (Wellisch, 2006, p. 115). The present paper newly shows that the distortion threat in a MA with capital and household mobility is over-taxation of capital by the city which is aimed at preventing excessive traffic congestion in the CBD.

The second externality is the public good spillover or its consumption by non-residents. A well-known result is that these spillover effects drive jurisdictions to under-provide local public goods, since in "decentralized decision-making, the value of local public services to nonresidents is ignored" (Gordon, 1983, p. 578). This result also relies on the assumption of immobile residents. As shown in Wellisch (1993), relaxing this assumption leads to efficient local public good provision, since local governments consider the welfare of mobile non-residents. Our analysis shows that despite residents' mobility, local public good spillovers lead local governments to distort their public good provision in order to prevent excessive traffic congestion. However, under-provision occurs only in the city; towns over-provide public goods.

\subsection{Local labor tax/subsidy: a first-class policy instrument}

This paper shows that labor taxation/subsidy is a first-best tax instrument. However, most work on tax competition with commuting and source-based taxation on labor considers it, a second-best instrument. In this literature, two main reasons explain why local governments make use of a labor tax/subsidy.

First, a labor tax might be imposed for budgetary reasons in the unavailability of any other tax relying on a less mobile tax base. This requires that labor mobility is limited, usually by commuting costs. ${ }^{53}$ For example, in a model with symmetric jurisdictions, Braid (2000) shows that if local public goods are financed by a labor tax and a capital tax, only the former is imposed in the presence of commuting costs. ${ }^{54}$ In a model with a city and towns, Gaigné et al.

\footnotetext{
${ }^{53}$ An exception is Braid (1996) in which labor limited mobility results from the fixity of business land.

${ }^{54}$ If commuting costs decrease the labor tax also decreases, until commuting costs reach zero when labor is no longer taxed and no public goods are provided. See proposition 3 and 4 in Braid (2000).
} 
(2016) find a related result which shows that the city exploits labor limited mobility induced by commuting costs to impose a positive business tax, while towns set a zero tax. ${ }^{55}$ The link between labor taxation and commuting costs is however broken if a less distortive tax allows the financing of the public good. ${ }^{56}$

Second, a labor tax/subsidy can be used also for tax exporting purposes that is, shifting the tax burden to nonresidents. This case is illustrated in Peralta (2007) which shows that the labor importer jurisdiction taxes labor while the labor exporter subsidizes it. ${ }^{57}$ For tax exporting also, local governments prefer an undistortive instrument such as a land tax to a distortive tax on labor.

In the present paper, the availability of an undistortive tax on land allows for both local budget balancing and tax exporting. Towns subsidize labor for a different reason - that of internalizing traffic congestion costs. This can be considered the first-best or natural role of local labor taxation/subsidy in a MA.

\section{Conclusion}

This paper investigates how local governments such as municipalities address one of the biggest MA challenges: traffic congestion. Traffic congestion is a typical MA negative externality, similar to air, waste and noise pollutions, which results from the spatial agglomeration of jobs and household mobility. It is also considered a major problem by policy makers and economists due to its significant costs (e.g. fuel, working time wasted, stress, maintenance of congested roads, greenhouse gas emissions).

The study develops a new urban tax competition model which links local public economics and urban economics models. The analysis shows that common local fiscal instruments may be used by municipalities to curb overwhelming traffic congestion in MA centers. Specifically, by charging high capital tax rates and low residential tax rates, the central city can make its business district less attractive to workers which reduces traffic congestion. Since many public goods (e.g. safety, public hygiene and roads) are consumed not only by the municipality's residents but also by its workers, local public good provision can also be employed. To free up the MA's roads, the central city and the suburban towns respectively can reduce and increase their public good provision. The aforementioned instruments are however only second-best

\footnotetext{
${ }^{55}$ See proposition 2 in Gaigné et al. (2016). Notice that Gaigné et al. consider a poll tax on firms. However, since labor is the only input, the economic incidence of this tax is essentially similar to that of a labor tax.

56 This is shown in proposition 2 in Braid (2000) which indicates that if a tax on immobile residents is available, labor taxation is no longer applied.

${ }^{57}$ See proposition 2 in Peralta (2007). Also, see Gordon (1983) for a similar early tax exporting result in a model with residents' mobility.
} 
tools; the paper shows that the most efficient way to regulate traffic congestion is to allow suburban towns to provide firms with local labor subsidies.

Decentralized local labor subsidies could profitably complement national (e.g. lane tolls, gasoline taxes) and regional (e.g. integrated public transport) solutions. These solutions often receive poor public support. ${ }^{58}$ Local labor subsidies would be more acceptable; unlike congestion charges, they are perceived as a rewarding rather than a punitive instrument. Moreover, local governments are better informed than higher level authorities about their residents' needs and can adapt their policies to their preferences. For instance, in a town where voters complain hugely about time spent every day stuck in traffic jams, the local mayor will be nudged to develop the town's business district through the provision of labor subsidies.

In practice, local labor subsidies are critically missing, mainly because they are at odds with competition policy. Subsidies are strictly controlled by supranational authorities such as the European Commission, the World Trade Organization and the West African Economic and Monetary Union (OECD, 2010). ${ }^{59}$ In view of the significant market failures in MAs, these local level restrictions would seem worthy of further consideration.

The easiest way to implement the subsidies recommended in this paper would be to let the residents of each town vote on the level of monetary subsidy per worker, and to provide the subsidy in the form of a tax credit to all local firms based on the number of their employees. Notice that this fiscal instrument differs from most existing local development subsidies and tax credits, for instance in the US, that are often arbitrarily implemented by local governments and are based on multiple performance criteria rather than focusing on the number of employees. ${ }^{60}$ An alternative solution is to subsidize workers rather than firms. For instance, town authorities could provide local workers with direct monetary subsidies or in-kind advantages such as luncheon vouchers, free parking places or public transport rebates.

The constantly growing economic significance of MAs worldwide means that many important challenges hitherto considered national will need to be rethought at the metropolitan level. The paper contributes to this overall discussion by inviting national policy makers to reshape over-concentrated MAs to achieve greater polycentrism. They would profitably provide

\footnotetext{
${ }^{58}$ Congestion charges are unpopular with members of the public. This is exemplified by the 2019 political crisis in France involving the 'Gilets jaunes' which was triggered by a rise in gasoline taxes. Also, public transport solutions are not unanimously favored. EC (2013) surveyed 83 European municipalities and reports that $25 \%$ of individuals are not satisfied with their public transport - and this figure rose to $75 \%, 63 \%$ and $48 \%$ respectively in Naples, Rome and Budapest.

59 All World Trade Organization members signed the Agreement on Subsidies and Countervailing Mechanisms following the Uruguay Round in 1995.

${ }^{60}$ See footnote 9 for more details about existing development subsidies.
} 
local authorities with more means to foster the development of strong secondary economic poles.

\section{References}

Agrawal, D. R., W. H. Hoyt, and J. D. Wilson (2019). Tax competition with mobile labor, residents, and capital. Working paper.

Arnott, R., A. De Palma, and R. Lindsey (1993). A structural model of peak-period congestion: A traffic bottleneck with elastic demand. The American Economic Review, 161-179.

Baldwin, R. E. and P. Krugman (2004). Agglomeration, integration and tax harmonisation. European Economic Review 48(1), 1-23.

Bergstrom, T. C. and R. P. Goodman (1973). Private demands for public goods. The American Economic Review 63(3), 280-296.

Bouvier, M. (2004). Les finances locales, Volume 1. Lgdj.

Braid, R. M. (1996). Symmetric Tax Competition with Multiple Jurisdictions in Each Metropolitan Area. American Economic Review 86(5), 1279-90.

Braid, R. M. (2000). A spatial model of tax competition with multiple tax instruments. Journal of Urban Economics 47(1), 88 - 114.

Brueckner, J. K. (2000). A Tiebout/tax-competition model. Journal of Public Economics $77(2), 285-306$.

Brülhart, M., S. Bucovetsky, and K. Schmidheiny (2015). Chapter 17 - taxes in cities. In J. V. H. Gilles Duranton and W. C. Strange (Eds.), Handbook of Regional and Urban Economics, Volume 5 of Handbook of Regional and Urban Economics, pp. 1123 - 1196. Elsevier.

Bucovetsky, S. (1991). Asymmetric tax competition. Journal of Urban Economics $30(2)$, $167-181$.

Bucovetsky, S. (2009). An index of capital tax competition. International tax and public finance 16(6), 727-752.

Burbidge, J. and K. Cuff (2005). Capital tax competition and returns to scale. Regional science and urban economics 35(4), 353-373. 
Cavailhes, J., C. Gaigné, T. Tabuchi, and J.-F. Thisse (2007). Trade and the structure of cities. Journal of Urban Economics 62 (3), 383-404.

Charlot, S. and S. Paty (2007). Market access effect and local tax setting: evidence from french panel data. Journal of Economic Geography 7(3), 247-263.

Combes, P.-P., G. Duranton, and L. Gobillon (2018). The costs of agglomeration: House and land prices in french cities. The Review of Economic Studies 86(4), 1556-1589.

Denant-Boèmont, L., C. Gaigné, and R. Gaté (2018). Urban spatial structure, transportrelated emissions and welfare. Journal of Environmental Economics and Management 89, $29-45$.

EC, E. C. (2013). Quality of life in European cities. Flash Eurobarometer 366.

Elkin, S. L. (2015). City and regime in the American republic. University of Chicago Press.

Epple, D. and A. Zelenitz (1981). The Implications of Competition among Jurisdictions: Does Tiebout Need Politics? Journal of Political Economy 89(6), 1197-1217.

Fujita, M. (1989). Urban economic theory: land use and city size. Cambridge university press.

Gaigné, C., S. Riou, and J.-F. Thisse (2016). How to make the metropolitan area work? neither big government, nor laissez-faire. Journal of Public Economics 134, 100-113.

Gordon, R. H. (1983). An optimal taxation approach to fiscal federalism. The Quarterly Journal of Economics 98(4), 567-586.

Hoyt, W. H. (1991). Competitive jurisdictions, congestion, and the Henry George Theorem : When should property be taxed instead of land? Regional Science and Urban Economics 21(3), 351-370.

Hoyt, W. H. (1992). Market power of large cities and policy differences in metropolitan areas. Regional Science and Urban Economics 22(4), 539-558.

Janeba, E. and S. Osterloh (2013). Tax and the city a: A theory of local tax competition. Journal of Public Economics 106(0), 89-100.

Kächelein, H. (2014). Asymmetric capital tax competition and choice of tax rate. International Tax and Public Finance 21 (1), 50-65.

Krelove, R. (1993). The persistence and inefficiency of property tax finance of local public expenditures. Journal of Public Economics 51(3), 415-435. 
Legras, S. (2019). Commuting in happyville: Taxation with interjurisdictional commuting and pollution. Journal of Public Economic Theory 21(2), 201-218.

Luthi, E. and K. Schmidheiny (2013). The effect of agglomeration size on local taxes. Journal of Economic Geography 14(2), 265-287.

Ly, T. (2018a). Sub-metropolitan tax competition with household and capital mobility. International Tax and Public Finance 25(5), 1129-1169.

Ly, T. (2018b). Tax competition within Metropolitan areas. Ph. D. thesis, Université de Lyon.

Ly, T. and S. Paty (2019). Local taxation and tax base mobility: Evidence from France. Regional Science and Urban Economics, https://doi.org/10.1016/j.regsciurbeco.2019.01.010.

Matsumoto, M. (1998). A note on tax competition and public input provision. Regional Science and Urban Economics 28(4), 465-473.

Matsumoto, M. (2000). A tax competition analysis of congestible public inputs. Journal of Urban Economics 48(2), 242-259.

Oates, W. E. (1972). Fiscal federalism. Harcourt Brace.

OECD (2010). Competition, State Aids and Subsidies. OECD Policy Roundtables.

OECD (2015). The Metropolitan Century: Understanding urbanisation and its consequences. OECD Publishing.

Parry, I. W. H. (2002). Comparing the efficiency of alternative policies for reducing traffic congestion. Journal of public economics 85(3), 333-362.

Peralta, S. (2007). Political support for tax decentralization. Journal of Public Economic Theory 9(6), 1013-1030.

Pigou, A. C. (1912). Wealth and welfare. Macmillan and Company.

Preston, J. (2012). Integration for seamless transport. International Transport Forum Discussion Papers, No. 2012/01.

Rouwendal, J. and E. T. Verhoef (2006). Basic economic principles of road pricing: From theory to applications. Transport policy 13(2), 106-114.

Sas, W. (2017). Can fiscal equalisation mitigate tax competition? ad valorem and residencebased taxation in a federation. International Tax and Public Finance 24(5), 817-853. 
Sherwood-Call, C. (1986). The labor tax as an alternative revenue source. In Proceedings of the Annual Conference on Taxation Held under the Auspices of the National Tax AssociationTax Institute of America, pp. 86-93.

Sjoquist, D. L. and R. Stoycheva (2012). Local revenue diversification: User charges, sales taxes, and income taxes. The Oxford handbook of state and local government finance, 429 462.

Sullivan, D. M. and G. P. Green (1999). Business subsidies ad municipal controls. Journal of Urban Affairs 21(3), 267-279.

Tannenwald, R. (2002). Are state and local revenue systems becoming obsolete? National Tax Journal 55(3), 467-489.

Thomas, K. (2010). Investment incentives and the global competition for capital. Springer.

Tiebout, C. M. (1956). A Pure Theory of Local Expenditures. Journal of Political Economy 64, 416.

TomTom (2018). TomTom Traffic Index. https://www.tomtom.com/en_gb/traffic-index/ (accessed 19 June 2019).

UN (2013). World Population Prospects: The 2012 Revision.

Vickrey, W. S. (1963). Pricing in urban and suburban transport. The American Economic Review 53(2), 452-465.

Walters, A. A. (1961). The theory and measurement of private and social cost of highway congestion. Econometrica: Journal of the Econometric Society, 676-699.

Warner, M. E. and L. Zheng (2013). Business incentive adoption in the recession. Economic Development Quarterly 27(2), 90-101.

Wellisch, D. (1993). On the decentralized provision of public goods with spillovers in the presence of household mobility. Regional Science and Urban Economics 23(5), 667-679.

Wellisch, D. (2006). Theory of Public Finance in a Federal State. Number 9780521026871 in Cambridge Books. Cambridge University Press.

Wellisch, D. and J. Hulshorst (2000). A Second-Best Theory of Local Government Policy. International Tax and Public Finance 7(1), 5-22.

Wildasin, D. (1986). Urban public finance. Routledge. 
Wildasin, D. E. (1980). Locational efficiency in a federal system. Regional Science and Urban Economics 10(4), 453-471.

Wildasin, D. E. (1989). Interjurisdictional capital mobility: Fiscal externality and a corrective subsidy. Journal of urban economics 25(2), 193-212.

Wilson, J. D. (1986). A theory of interregional tax competition. Journal of Urban Economics 19(3), 296-315.

Wilson, J. D. (1991). Tax competition with interregional differences in factor endowments. Regional Science and Urban Economics 21 (3), 423-451.

Wilson, J. D. (1995). Mobile Labor, Multiple Tax Instruments, and Tax Competition. Journal of Urban Economics 38(3), 333-356.

Wilson, J. D. (1999). Theories of Tax Competition. National Tax Journal 52(n. 2), 269-304.

Zenou, Y. (2009). Urban labor economics. Cambridge University Press.

Zodrow, G. R. and P. Mieszkowski (1986). Pigou, Tiebout, property taxation, and the underprovision of local public goods. Journal of Urban Economics 19(3), 356-370.

\section{Appendix A Individual land income}

According to the description made in section 3, the land income of an individual is:

$$
\Gamma=\mathcal{P}^{-1} \sum_{i=1}^{n}\left[\int_{-\mathcal{L}_{c} / n}^{0}\left[\rho_{i}(l)-\tau_{c}^{\mathcal{L}}\right] \mathrm{d} l+\int_{0}^{\mathcal{L}_{s_{i}}}\left[\rho_{i}(l)-\tau_{s_{i}}^{\mathcal{L}}\right] \mathrm{d} l\right]
$$

The objective of this appendix is to derive the explicit expression of the individual land income $\Gamma$ in equilibrium. To this aim, we first determine the equilibrium land rent function (subsection A.1) from which we derive the equilibrium individual land income (subsection A.2).

\section{A.1. Land rent function}

In this subsection, we determine the land rent function in equilibrium: the land rent $\rho_{i}(l)$ paid by households or firms as a function of their location $l$ on strip $i$. In business districts, the land rent is equal to the business bid land rent characterized in (17), so that:

$$
\left.\left.\rho_{i}(l)=F_{L}^{c} \quad l \in\right]-\frac{\mathcal{L}_{c}}{n},-\mathcal{A}\right],
$$




$$
\left.\left.\rho_{i}(l)=F_{L}^{s_{i}}, \quad l \in\right] \mathcal{C}_{i}, \mathcal{D}_{i}\right]
$$

In residential land, the land rent is equal to residents' bid land rent characterized in (12), so that:

$$
\begin{array}{ll}
\rho_{i}(l)=w_{c}-\int_{-\mathcal{A}}^{l}\left[t+a\left(\mathcal{B}_{i}-z\right)\right] \mathrm{d} z+\Lambda^{c c}-u, & l \in]-\mathcal{A}, 0] \\
\rho_{i}(l)=w_{c}-\int_{-\mathcal{A}}^{l}\left[t+a\left(\mathcal{B}_{i}-z\right)\right] \mathrm{d} z+\Lambda^{s_{i} c}-u, & \left.l \in] 0, \mathcal{B}_{i}\right], \\
\rho_{i}(l)=w_{s_{i}}-\int_{l}^{\mathcal{C}_{i}}\left[t+a\left(z-\mathcal{B}_{i}\right)\right] \mathrm{d} z+\Lambda^{s_{i} s_{i}}-u, & \left.l \in] \mathcal{B}_{i}, \mathcal{C}_{i}\right] \\
\rho_{i}(l)=w_{s_{i}}-\int_{\mathcal{D}_{i}}^{l}\left[t+a\left(\mathcal{L}_{s}-z\right)\right] \mathrm{d} z+\Lambda^{s_{i} s_{i}}-u, & \left.l \in] \mathcal{D}_{i}, \mathcal{L}_{s}\right] .
\end{array}
$$

where $T\left(l, l^{\prime}\right)$ has been replaced by its the definition (7). A typical land rent function characterized by (A.2)-(A.7) is represented in Figure A.1.

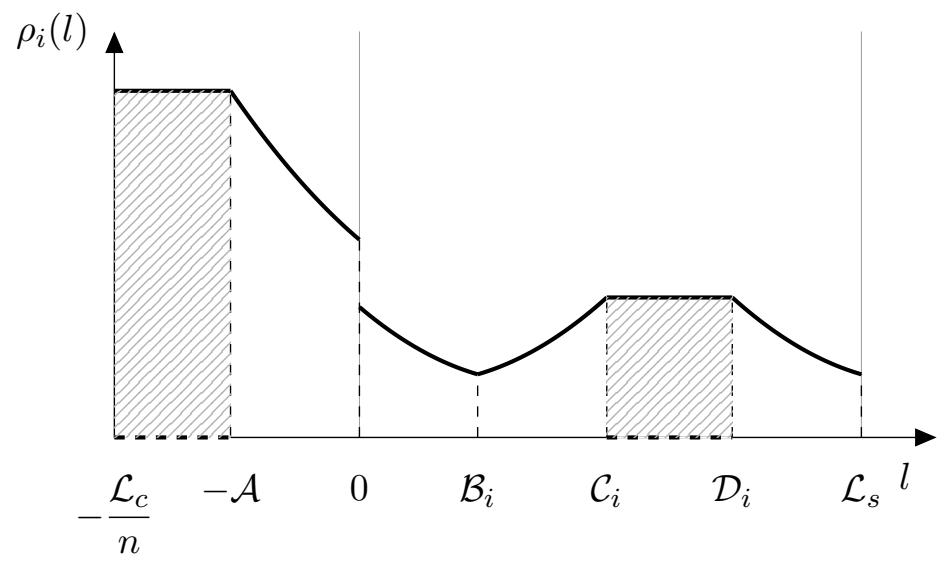

Figure A.1. Land rent function over a strip linking the city $c$ to the town $s_{i}$. Convexity of the land rent function (ie. concavity of the commuting cost function) results from traffic congestion $(a>0)$ : the closest the business district, the less individuals suffer from the cumulative effect of traffic congestion on roads.

Using (19) and (e.6) to eliminate $\Lambda^{s_{i} s_{i}}, \Lambda^{s_{i} s_{i}}$ and $\Lambda^{s_{i} s_{i}}$, (A.4)-(A.7) become:

$$
\begin{array}{ll}
\rho_{i}(l)=-\int_{-\mathcal{A}}^{l}\left[t+a\left(\mathcal{B}_{i}-z\right)\right] \mathrm{d} z+F_{L}^{c}, & l \in]-\mathcal{A}, 0] \\
\rho_{i}(l)=\int_{l}^{\mathcal{B}_{i}}\left[t+a\left(\mathcal{B}_{i}-z\right)\right] \mathrm{d} z-\int_{\mathcal{B}_{i}}^{\mathcal{C}_{i}}\left[t+a\left(z-\mathcal{B}_{i}\right)\right] \mathrm{d} z+F_{L}^{s_{i}}, & \left.l \in] 0, \mathcal{B}_{i}\right], \\
\rho_{i}(l)=-\int_{l}^{C_{i}}\left[t+a\left(z-\mathcal{B}_{i}\right)\right] \mathrm{d} z+F_{L}^{s_{i}}, & \left.l \in] \mathcal{B}_{i}, \mathcal{C}_{i}\right]
\end{array}
$$




$$
\left.\left.\rho_{i}(l)=-\int_{\mathcal{D}_{i}}^{l}\left[t+a\left(\mathcal{L}_{s}-z\right)\right] \mathrm{d} z+F_{L}^{s_{i}}, \quad l \in\right] \mathcal{D}_{i}, \mathcal{L}_{s}\right]
$$

\section{A.2. Equilibrium land income}

We can now derive the explicit form of the individual land income in equilibrium. To do so, we need to insert (A.2)-(A.2) and (A.8)-(A.11) into (A.1) and collect terms, as described in this subsection. Since land rent is constant within business districts and the land rent paid by suburban residents working where they live is symmetric on both side of the SBD (see Figure A.1), we have:

$$
\begin{aligned}
& \int_{-\frac{\mathcal{L}_{c}}{n}}^{0}\left(\rho_{i}(l)-\tau_{c}^{\mathcal{L}}\right) \mathrm{d} l=\int_{-\mathcal{A}}^{0}\left(\rho_{i}(l)-\tau_{c}^{\mathcal{L}}\right) \mathrm{d} l+\left(F_{L}^{c}-\tau_{c}^{\mathcal{L}}\right) \frac{L_{c}}{n} \\
& \int_{0}^{\mathcal{L}_{s}}\left(\rho_{i}(l)-\tau_{s_{i}}^{\mathcal{L}}\right) \mathrm{d} l=\int_{0}^{\mathcal{B}_{i}}\left(\rho_{i}(l)-\tau_{s_{i}}^{\mathcal{L}}\right) \mathrm{d} l+2 \int_{\mathcal{B}_{i}}^{\mathcal{C}_{i}}\left(\rho_{i}(l)-\tau_{s_{i}}^{\mathcal{L}}\right) \mathrm{d} l+\left(F_{L}^{s_{i}}-\tau_{s_{i}}^{\mathcal{L}}\right) L_{s_{i}}
\end{aligned}
$$

Then, from the aggregate land rent definition (A.1), we obtain:

$$
\Gamma=\mathcal{P}^{-1} \sum_{i=1}^{n}\left[\mathcal{I}_{c_{i}}+\mathcal{I}_{s_{i}}+n^{-1}\left(F_{L}^{c} L_{c}-\tau_{c}^{\mathcal{L}} \mathcal{L}_{c}\right)+\left(F_{L}^{s_{1}} L_{s_{1}}-\tau_{s_{1}}^{\mathcal{L}} \mathcal{L}_{s}\right)\right]
$$

where

$$
\mathcal{I}_{c_{i}} \equiv \int_{-\mathcal{A}}^{0} \rho_{i}(l) \mathrm{d} l, \quad \mathcal{I}_{s_{i}} \equiv \int_{0}^{\mathcal{B}_{i}} \rho_{i}(l) \mathrm{d} l+2 \int_{\mathcal{B}_{i}}^{\mathcal{C}_{i}} \rho_{i}(l) \mathrm{d} l
$$

Inserting (A.8)-(A.10) into (A.13), replacing $\mathcal{A}, \mathcal{B}_{i}$ and $\mathcal{C}_{i}$ by their definitions (3)-(5), and integrating, we obtain:

$$
\begin{aligned}
& \mathcal{I}_{c_{i}}=\frac{t+a\left(R_{s_{i}}-W_{s_{i}}\right)}{2}\left(\frac{R_{c}}{n}\right)^{2}-\frac{a}{3}\left(\frac{R_{c}}{n}\right)^{3}+F_{L}^{c} \frac{R_{c}}{n} \\
& \mathcal{I}_{s_{i}}=\frac{a R_{s_{i}}^{3}}{6}+\frac{R_{s_{i}}^{2}\left(t-a W_{s_{i}}\right)}{2}+\frac{W_{s_{i}}^{2}\left(6 t-a W_{s_{i}}\right)+3 R_{s_{i}} W_{s_{i}}\left(a W_{s_{i}}-4 t\right)}{8}+F_{L}^{s_{i}} R_{s_{i}}
\end{aligned}
$$

Then, replacing $\tau_{c}^{\mathcal{L}}$ and $\tau_{s_{i}}^{\mathcal{L}}$ in (A.12) using the local budget constraints (20), and replacing $L_{c}$ and $L_{s_{i}}$ using the land occupation condition (2), we obtain:

$$
\begin{aligned}
\Gamma=\mathcal{P}^{-1} \sum_{i=1}^{n}\left[\mathcal{I}_{c_{i}}+\mathcal{I}_{s_{i}}\right. & +F_{L}^{s_{i}}\left(\mathcal{L}_{s_{i}}-R_{s_{i}}\right)+\tau_{s_{i}}^{R} R_{s_{i}}+\tau_{s_{i}}^{K} K_{s_{i}}+\tau_{s_{i}}^{W} W_{s_{i}}-C^{s_{i}} \\
& \left.+n^{-1}\left(F_{L}^{c}\left(\mathcal{L}_{c}-R_{c}\right)+\tau_{c}^{R} R_{c}+\tau_{c}^{K} K_{c}+\tau_{c}^{W} W_{c}-C^{c}\right)\right]
\end{aligned}
$$

which is the explicit expression of the individual land income $\Gamma$ in equilibrium, with $\mathcal{I}_{c_{i}}$ and $\mathcal{I}_{s_{i}}$ defined in (A.14) and (A.15). 
Since all towns are identical, the following appendices drop index $i$ for convenience. However, notice that a given town's decision does not engage other towns.

\section{Appendix B Proof of Result 1}

The purpose of this section is to derive the municipalities' optimal policy rules when the tax instrument set includes a tax/subsidy on labor. Specifically, we prove the towns' optimal policy rules (21a)-(24a) in subsection B.1 and the city's optimal policy rules (21b)-(24b) in subsection B.2. Before proceeding, recall that since $F^{j}$ is homogenous of degree 1 , we have the following Euler's formulas for each $X \in\{W ; K, L\}$ :

$$
\begin{aligned}
& F_{W}^{j} W+F_{K}^{j} K+F_{L}^{j} L=F^{j}, \\
& F_{W X}^{j} W+F_{K X}^{j} K+F_{L X}^{j} L=0,
\end{aligned}
$$

As explained in subsection 3.4, the equilibrium level of $K_{c}, K_{s}, R_{c}, R_{s}, W_{c}$ and $W_{s}$ are fully defined by the equations (e.1)-(e.6) which are restated here for convenience:

$$
\begin{aligned}
& F_{K}^{c}-\tau_{c}^{K}-\left(F_{K}^{s}-\tau_{s}^{K}\right)=0 \\
& F_{W}^{c}-\tau_{c}^{W}+U^{s c}-\int_{-\frac{R_{c}}{n}}^{R_{s}-W_{s}}\left[t+a\left(R_{s}-W_{s}-z\right)\right] d z \\
& -\left(F_{W}^{s}-\tau_{s}^{W}+U^{s s}-\int_{R_{s}-W_{s}}^{R_{s}-\frac{W_{s}}{2}}\left[t+a\left(z-R_{s}+W_{s}\right)\right] d z\right)=0 \\
& F_{W}^{c}-\tau_{c}^{W}-F_{L}^{c}+U^{c}+U^{c c}-\tau_{c}^{R}-\left(F_{W}^{s}-\tau_{s}^{W}-F_{L}^{s}+U^{s}+U^{s s}-\tau_{s}^{R}\right)=0 \\
& \mathcal{P}-W_{c}-n W_{s}=0 \\
& \mathcal{P}-R_{c}-n R_{s}=0 \\
& \mathcal{K}-K_{c}-n K_{s}=0
\end{aligned}
$$

where (A.20) is obtained by replacing $T\left(l, l^{\prime}\right), \mathcal{A}, \mathcal{B}$ and $\mathcal{C}$ by their definitions (7) and (3)-(5) in (e.6).

\section{B.1. Optimal policy rules of a town}

In this subsection we prove the representative town's optimal policy rules (21a)-(24a) when labor taxation/subsidy is available. The utility of the resident of $s$ living the closest from her home town SBD is:

$$
x_{s}+U^{s}+U^{s s}
$$


and her budget constraint is:

$$
x_{s s}+\rho(\mathcal{C})=w_{s}+r k+\Gamma-\tau_{s}^{R},
$$

with $\rho(\mathcal{C})=F_{L}^{s}$. Replacing $w_{s}$ using (15), it follows that the municipalities' program is to maximize:

$$
-F_{L}^{s}+F_{W}^{s}-\tau_{s}^{W}+r k+\Gamma+U^{s}+U^{s s}-\tau_{s}^{R},
$$

choosing $\tau_{s}^{R}, \tau_{s}^{K}, G_{s}, W_{s}, R_{s}, K_{s}$, subject to constraints (A.19), (A.20) and (A.21) to which we respectively associate the Lagrange multipliers $\lambda_{1}, \lambda_{2}$ and $\lambda_{3}$. The variables $r, k$ and the variables of the city $X_{c}$ and those of the other towns $X_{s_{j}}$ are exogenous from the atomistic representative town's viewpoint - especially, in the aggregate land rent $\Gamma$ defined in (A.16). The business land $L_{s}$ has been replaced into the production function using the land occupation condition (2).

From the above program, we can derive the first-order conditions. The first-order conditions with respect to $\tau_{s}^{R}, \tau_{s}^{K}, \tau_{s}^{W}$ and $G_{s}$ are respectively:

$$
\begin{aligned}
& \frac{R_{s}}{\mathcal{P}}+\lambda_{3}-1=0 \\
& \frac{K_{s}}{\mathcal{P}}+\lambda_{1}=0 \\
& \frac{W_{s}}{\mathcal{P}}+\lambda_{2}+\lambda_{3}-1=0 \\
& \left(1-\lambda_{3}\right) U_{G}^{s}+\left(1-\lambda_{2}-\lambda_{3}\right) U_{G}^{s s}-\frac{C_{G}^{s}}{\mathcal{P}}=0 .
\end{aligned}
$$

The first-order condition with respect to $R_{s}$ is:

$$
\begin{aligned}
\frac{\tau_{s}^{R}}{\mathcal{P}}+\frac{t}{\mathcal{P}}\left(R_{s}-\frac{3 W_{s}}{2}-\mathcal{P} \lambda_{2}\right) & +\frac{a}{2 \mathcal{P}}\left[R_{s}^{2}+\frac{3 W_{s}^{2}}{4}-\frac{R_{c}^{2}}{n^{2}}-2 R_{s} W_{s}+\left(W_{s}-\frac{R_{c}}{n}-R_{s}\right) 2 \mathcal{P} \lambda_{2}\right] \\
& -\left(\frac{\mathcal{L}_{s}}{\mathcal{P}}+\lambda_{3}-1\right) F_{L L}^{s}+\lambda_{1} F_{L K}^{s}+\left(\lambda_{2}+\lambda_{3}-1\right) F_{L W}^{s}=0
\end{aligned}
$$

The first-order condition with respect to $K_{s}$ is:

$$
\frac{\tau_{s}^{K}}{\mathcal{P}}+\left(\frac{\mathcal{L}_{s}}{\mathcal{P}}+\lambda_{3}-1\right) F_{K L}^{s}-\lambda_{1} F_{K K}^{s}-\left(\lambda_{2}+\lambda_{3}-1\right) F_{K W}^{s}=0
$$

And, the first-order condition with respect to $W_{s}$ is:

$$
\frac{\tau_{s}^{W}}{\mathcal{P}}-\frac{3 t}{2 \mathcal{P}}\left(R_{s}-W_{s}-\lambda_{2} \mathcal{P}\right)+\frac{a}{2 \mathcal{P}}\left[\frac{R_{c}^{2}}{n^{2}}+\frac{3 R_{s} W_{s}}{2}-R_{s}^{2}-\frac{3 W_{s}^{2}}{4}+\left(\frac{R_{c}}{n}+R_{s}-\frac{3}{4} W_{s}\right) 2 \lambda_{2} \mathcal{P}\right]
$$




$$
+\left(\frac{\mathcal{L}_{s}}{\mathcal{P}}+\lambda_{3}-1\right) F_{W L}^{s}-\lambda_{1} F_{W K}^{s}-\left(\lambda_{2}+\lambda_{3}-1\right) F_{W W}^{s}=0
$$

The first-order conditions with respect to the tax instruments (A.25)-(A.27) entail:

$$
\lambda_{3}-1=-\frac{R_{s}}{\mathcal{P}}, \quad \lambda_{1}=-\frac{K_{s}}{\mathcal{P}}, \quad \lambda_{2}+\lambda_{3}-1=-\frac{W_{s}}{\mathcal{P}}, \quad \lambda_{2}=\frac{R_{s}-W_{s}}{\mathcal{P}}
$$

Then, using Euler's identities (A.18) and substituting $\mathcal{L}_{s}$ from (2), we have:

$$
\left(\frac{\mathcal{L}_{s}}{\mathcal{P}}+\lambda_{3}-1\right) F_{X L}^{s}-\lambda_{1} F_{X K}^{s}-\left(\lambda_{2}+\lambda_{3}-1\right) F_{X W}^{s}=0, \quad X \in\{K ; W\}
$$

And, from (e.2) and (e.3), we have:

$$
R_{c}+n R_{s}=W_{c}+n W_{s}
$$

Inserting(A.32) and (A.33) into the first-order conditions with respect to public good provision (A.28), population (A.29), capital (A.30) and labor (A.31), substituting $R_{c}$ using (A.34) and collecting terms implies:

$$
\begin{aligned}
& R_{s} U_{G}^{s}+W_{s} U_{G}^{s s}-C_{G}^{s}=0 \\
& \tau_{s}^{R}=\frac{t W_{s}}{2}+\frac{a}{2}\left(\frac{W_{c}^{2}}{n^{2}}+\frac{W_{s}^{2}}{4}\right) \\
& \tau_{s}^{K}=0 \\
& \tau_{s}^{W}=\frac{a}{2}\left(\frac{W_{s}^{2}}{4}-\frac{W_{c}^{2}}{n^{2}}\right)
\end{aligned}
$$

which proves conditions (22a)-(24a) in Result 1 .

\section{B.2. Optimal policy rules of the city}

In this subsection we prove the city's optimal policy rules (21b)-(24b) when labor taxation/subsidy is available. Since the central municipality regards all towns as symmetric, the aggregate land rent becomes:

$$
\begin{aligned}
\Gamma=\mathcal{P}^{-1}\left[n \left(\mathcal{I}_{c}+\mathcal{I}_{s}\right.\right. & \left.+F_{L}^{s}\left(\mathcal{L}_{s}-R_{s}\right)+\tau_{s}^{R} R_{s}+\tau_{s}^{K} K_{s}+\tau_{s}^{W} W_{s}-C^{s}\right) \\
& \left.+F_{L}^{c}\left(\mathcal{L}_{c}-R_{c}\right)+\tau_{c}^{R} R_{c}+\tau_{c}^{K} K_{c}+\tau_{c}^{W} W_{c}-C^{c}\right]
\end{aligned}
$$

The utility of the resident of $c$ living the closest from the CBD is:

$$
x_{c c}+U^{c}+U^{c c},
$$


and her budget constraint is:

$$
x_{c c}+\rho(-\mathcal{A})=w_{c}+r k+\Gamma-\tau_{c}^{R} .
$$

with $\rho(-\mathcal{A})=F_{L}^{c}$. Replacing $w_{c}$ and $r$ using (15) and (16), it follows that the municipalities' program is to maximize:

$$
-F_{L}^{c}+F_{W}^{c}-\tau_{c}^{W}+\left(F_{K}^{c}-\tau_{c}^{K}\right) k+\Gamma+U^{c}+U^{c c}-\tau_{c}^{R},
$$

choosing $\tau_{c}^{R}, \tau_{c}^{K}, G_{c}, G_{s}, W_{j}, R_{j}, K_{j}$, where $j \in\{c ; s\}_{i \in \llbracket 1, n \rrbracket}$, and subject to constraints (A.19), (A.20), (A.21), (A.24), (A.22) and (A.23) to which we respectively associate the Lagrange multipliers $\mu_{1}, \mu_{2}, \mu_{3}, \mu_{4}, \mu_{5}$ and $\mu_{6}$. Moreover, business land $L_{c}$ and $L_{s}$ have been replaced into the production function using the land occupation condition (2).

From the above program, we can derive the first-order conditions. The first-order conditions with respect to $\tau_{c}^{R}, \tau_{c}^{K}, \tau_{c}^{W}$ and $G_{c}$ are respectively:

$$
\begin{aligned}
& \frac{R_{c}}{\mathcal{P}}-\mu_{3}-1=0 \\
& \frac{K_{c}}{\mathcal{P}}-\mu_{1}-k=0 \\
& \frac{W_{c}}{\mathcal{P}}-\mu_{2}-\mu_{3}-1=0 \\
& \left(1+\mu_{3}\right)\left(U_{G}^{c}+U_{G}^{c, c}\right)+\mu_{2} U_{G}^{s, c}-\frac{C_{G}^{c}}{\mathcal{P}}=0
\end{aligned}
$$

The first-order condition with respect to $R_{c}$ is:

$$
\begin{aligned}
& \frac{\tau_{c}^{R}}{\mathcal{P}}+\left[a\left(W_{s}-\frac{R_{c}}{n}-R_{s}\right)-t\right] \frac{R_{c}+\mu_{2} \mathcal{P}}{n \mathcal{P}} \\
& -\left(\frac{\mathcal{L}_{c}}{\mathcal{P}}-\mu_{3}-1\right) F_{L L}^{c}-\left(\mu_{1}+k\right) F_{K L}^{c}-\left(\mu_{2}+\mu_{3}+1\right) F_{W L}^{c}-\mu_{5}=0
\end{aligned}
$$

The first-order condition with respect to $R_{s}$ is:

$$
\begin{aligned}
& \frac{n \tau_{s}^{R}}{\mathcal{P}}+\frac{t}{\mathcal{P}}\left(n R_{s}-\frac{3 n W_{s}}{2}-\mu_{2} \mathcal{P}\right)+\frac{a n}{2 \mathcal{P}}\left(\frac{3 W_{s}^{2}}{4}+R_{s}^{2}-2 R_{s} W_{s}-\frac{R_{c}^{2}}{n^{2}}+\left(W_{s}-\frac{R_{c}}{n}-R_{s}\right) \frac{2 \mu_{2} \mathcal{P}}{n}\right) \\
& -\left(\frac{n \mathcal{L}_{s}}{\mathcal{P}}+\mu_{3}\right) F_{L L}^{s}+\mu_{1} F_{K L}^{s}+\left(\mu_{2}+\mu_{3}\right) F_{W L}^{s}-n \mu_{5}=0
\end{aligned}
$$

The first-order condition with respect to $K_{c}$ is:

$$
\frac{\tau_{c}^{K}}{\mathcal{P}}+\left(\frac{\mathcal{L}_{c}}{\mathcal{P}}-\mu_{3}-1\right) F_{K L}^{c}+\left(\mu_{1}+k\right) F_{K K}^{c}+\left(\mu_{2}+\mu_{3}+1\right) F_{W K}^{c}-\mu_{6}=0
$$


The first-order condition with respect to $K_{s}$ is:

$\frac{n \tau_{s}^{K}}{\mathcal{P}}+\left(\frac{n \mathcal{L}_{s}}{\mathcal{P}}+\mu_{3}\right) F_{K L}^{s}-\mu_{1} F_{K K}^{s}-\left(\mu_{2}+\mu_{3}\right) F_{W K}^{s}-n \mu_{6}=0$

The first-order condition with respect to $W_{c}$ is:

$\frac{\tau_{c}^{W}}{\mathcal{P}}+\left(\frac{\mathcal{L}_{c}}{\mathcal{P}}-\mu_{3}-1\right) F_{W L}^{c}+\left(\mu_{1}+k\right) F_{W K}^{c}+\left(\mu_{2}+\mu_{3}+1\right) F_{W W}^{c}-\mu_{4}=0$

The first-order condition with respect to $W_{s}$ is:

$$
\begin{aligned}
& \frac{n \tau_{s}^{W}}{\mathcal{P}}+\frac{3 t}{2 \mathcal{P}}\left[n\left(W_{s}-R_{s}\right)+\mu_{2} \mathcal{P}\right]+\frac{a n}{2 \mathcal{P}}\left(\frac{R_{c}^{2}}{n^{2}}+\frac{3 R_{s} W_{s}}{2}-R_{s}^{2}-\frac{3 W_{s}^{2}}{4}+\left(\frac{R_{c}}{n}+R_{s}-\frac{3}{4} W_{s}\right) \frac{2 \mathcal{P} \mu_{2}}{n}\right) \\
& +\left(\frac{n \mathcal{L}_{s}}{\mathcal{P}}+\mu_{3}\right) F_{W L}^{s}-\mu_{1} F_{W K}^{s}-\left(\mu_{2}+\mu_{3}\right) F_{W W}^{s}-n \mu_{4}=0
\end{aligned}
$$

We can now prove the optimal behavior rules when labor taxes are available (21b)-(24b). The first-order conditions with respect to the tax instruments (A.39)-(A.42) imply:

$$
\mu_{3}+1=\frac{R_{c}}{\mathcal{P}}, \quad \mu_{1}+k=\frac{K_{c}}{\mathcal{P}}, \quad \mu_{2}+\mu_{3}+1=\frac{W_{c}}{\mathcal{P}}, \quad \mu_{2}=\frac{W_{c}-R_{c}}{\mathcal{P}}
$$

which can also be written as:

$$
\mu_{3}=-\frac{n R_{s}}{\mathcal{P}}, \quad \mu_{1}=-\frac{n K_{s}}{\mathcal{P}}, \quad \mu_{2}+\mu_{3}=-\frac{n W_{s}}{\mathcal{P}}, \quad \mu_{2}=-\frac{n\left(W_{s}-R_{s}\right)}{\mathcal{P}}
$$

using conditions (A.22)-(A.24) and $\mathcal{K}=k \mathcal{P}$. Then, using Euler's identities (A.18) and substituting $\mathcal{L}_{j}, j \in\{c ; s\}$ from (2), we have:

$$
\begin{aligned}
& \left(\frac{\mathcal{L}_{c}}{\mathcal{P}}-\mu_{3}-1\right) F_{X L}^{c}+\left(\mu_{1}+k\right) F_{K X}^{c}+\left(\mu_{2}+\mu_{3}+1\right) F_{W X}^{c}-\mu_{6}=0 \\
& \left(\frac{n \mathcal{L}_{s}}{\mathcal{P}}+\mu_{3}\right) F_{X L}^{s}-\mu_{1} F_{X K}^{s}-\left(\mu_{2}+\mu_{3}\right) F_{W X}^{s}-n \mu_{6}=0
\end{aligned}
$$

Inserting (A.48)-(A.51) into each of the first-order conditions (A.42)-(A.47) entails respectively:

$$
\begin{aligned}
C_{G}^{c} & =R_{c}\left(U_{G}^{c}+U_{G}^{c, c}\right)+n W_{\mathrm{sc}} U_{G}^{s, c} \\
\tau_{c}^{R} & =\frac{t W_{c}}{n}+\frac{a W_{c}^{2}}{n^{2}}+\mathcal{P} \mu_{5} \\
\tau_{s}^{R} & =\frac{a W_{c}^{2}}{2 n^{2}}+\frac{t W_{s}}{2}+\frac{a W_{s}^{2}}{8}+\mathcal{P} \mu_{5} \\
\tau_{c}^{K} & =\mathcal{P} \mu_{6} \\
\tau_{s}^{K} & =\mathcal{P} \mu_{6}
\end{aligned}
$$




$$
\begin{aligned}
\tau_{c}^{W} & =\mathcal{P} \mu_{4} \\
\tau_{s}^{W} & =-\frac{a W_{c}^{2}}{2 n^{2}}+\frac{a W_{s}^{2}}{8}+\mathcal{P} \mu_{4}
\end{aligned}
$$

in which (A.22)-(A.24) and $\mathcal{K}=k \mathcal{P}$ have been used to collect terms. Condition (A.52) proves (24b). Moreover, inserting the taxation rules of the town (A.36)-(A.38) into (A.54), (A.56) and (A.58) implies $\mu_{4}=\mu_{5}=\mu_{6}=0$. Then, (A.52), (A.52), (A.52) become:

$$
\begin{aligned}
\tau_{c}^{R} & =\frac{t W_{c}}{n}+\frac{a W_{c}^{2}}{n^{2}} \\
\tau_{c}^{K} & =0 \\
\tau_{c}^{W} & =0
\end{aligned}
$$

which proves conditions (21b)-(23b).

\section{Appendix C Proof of Result 2}

The purpose of this section is to derive the municipalities' optimal policy rules when the tax instrument set includes a tax/subsidy on labor. Specifically, we prove the towns' optimal policy rules (32a)-(34a) in subsection C.1 and the city's optimal policy rules (32b)-(34b) in subsection C.2.

\section{C.1. Optimal policy rules of a town}

In this subsection we prove the representative town's optimal policy rules (32a)-(34a) when labor taxation/subsidy is available. The proof is based on the first-order conditions (A.25)(A.31). However, the first-order condition with respect to the labor tax (A.27) is ignored and $\tau_{s}^{W}$ is replaced by 0 everywhere it appears. Inserting the first-order conditions with respect to the tax instruments (A.25) and (A.26) into the first-order condition with respect to labor (A.31), substituting $\mathcal{L}_{s}$ from (2) and using Euler's theorem entails:

$$
\lambda_{2}+\lambda_{3}-1=-\frac{W_{s}}{\mathcal{P}}-\frac{\Phi}{\mathcal{P} D_{s}} .
$$

where

$$
\Phi \equiv \frac{a}{2}\left[\left(\frac{W_{c}}{n}\right)^{2}-\left(\frac{W_{s}}{2}\right)^{2}\right], \quad D_{s} \equiv \frac{3}{2} t+a\left(\frac{W_{c}}{n}+\frac{W_{s}}{4}\right)-F_{W W}^{s}
$$


The first-order conditions with respect to the tax instruments (A.25) and (A.26), and condition (A.62) entail:

$$
\lambda_{3}-1=-\frac{R_{s}}{\mathcal{P}}, \quad \lambda_{1}=-\frac{K_{s}}{\mathcal{P}}, \quad \lambda_{2}=\frac{R_{s}-W_{s}}{\mathcal{P}}-\frac{\Phi}{\mathcal{P} D_{s}}
$$

Then, using Euler's identities (A.18) and substituting $\mathcal{L}_{s}$ from (2), we have:

$$
\left(\frac{\mathcal{L}_{s}}{\mathcal{P}}+\lambda_{3}-1\right) F_{X L}^{s}-\lambda_{1} F_{X K}^{s}-\left(\lambda_{2}+\lambda_{3}-1\right) F_{X W}^{s}=\frac{\Phi}{\mathcal{P} D_{s}} F_{X W}^{s}, \quad X \in\{K ; W\}
$$

Inserting (A.62), (A.64) and (A.65) into the first-order conditions with respect to public good provision (A.28), population (A.29) and capital (A.30), substituting $R_{c}$ using (A.34) and collecting terms implies:

$$
\begin{aligned}
& R_{s} U_{G}^{s}+W_{s} U_{G}^{s, s}-C_{G}^{s}+\frac{\Phi U_{G}^{s, s}}{D_{s}}=0 \\
& \tau_{s}^{R}=\frac{t W_{s}}{2}+\frac{a}{2}\left(\frac{W_{c}^{2}}{n^{2}}+\frac{W_{s}^{2}}{4}\right)-\frac{\Phi\left(a W_{c}+n t-n F_{\mathrm{WL}}^{s}\right)}{n D_{s}} \\
& \tau_{s}^{K}=-\frac{\Phi F_{\mathrm{WK}}^{s}}{D_{s}}
\end{aligned}
$$

which proves conditions (32a)-(34a) in Result 2.

\section{C.2. Optimal policy rules of the city}

We now turn to the proof of the optimal behavior rules of the city when labor taxes are not available (32b)-(34b). The proof is based on the first-order conditions (A.39)-(A.47), ignoring the first-order condition with respect to the labor tax (A.41) is ignored and replacing $\tau_{c}^{W}$ and $\tau_{s}^{W}$ everywhere they appear by 0 .

Inserting the first-order conditions with respect to the tax instruments (A.25) and (A.26) into the first-order condition with respect to labor respectively of the city (A.46) and the town (A.47), substituting $\mathcal{L}_{j}, j \in\{c ; s\}$ from (2) and using Euler's theorem entails:

$$
\begin{aligned}
& \frac{W_{c}}{\mathcal{P}}-\mu_{2}-\mu_{3}-1=-\frac{\mu_{4}}{F_{W W}^{c}} \\
& \mu_{4}=-\frac{a\left(4 W_{c}^{2}-n^{2} W_{s}^{2}\right) F_{\mathrm{WW}}^{c}}{2 \mathcal{P}\left(4 a W_{c}+n\left(6 t+a W_{s}-4 n F_{\mathrm{WW}}^{c}-4 F_{\mathrm{WW}}^{s}\right)\right)}
\end{aligned}
$$

where (A.22)-(A.24) have been used to collect terms in (A.67). Combining (A.66) and (A.67) to eliminate $\mu_{4}$, we obtain:

$$
\mu_{2}+\mu_{3}+1=\frac{W_{c}}{\mathcal{P}}-\frac{n \Phi}{\mathcal{P} D_{c}}
$$


where $\Phi$ is as defined in (A.63) and:

$$
D_{c} \equiv \frac{3}{2} t+a\left(\frac{W_{c}}{n}+\frac{W_{s}}{4}\right)-F_{W W}^{s}-n F_{W W}^{c}
$$

The first-order conditions with respect to the tax instruments (A.39) and (A.40), and condition (A.62) entail:

$$
\mu_{3}+1=\frac{R_{c}}{\mathcal{P}}, \quad \mu_{1}+k=\frac{K_{c}}{\mathcal{P}}, \quad \mu_{2}=\frac{W_{c}-R_{c}}{\mathcal{P}}-\frac{n \Phi}{\mathcal{P} D_{c}}
$$

which can also be written as:

$$
\mu_{3}=-\frac{n R_{s}}{\mathcal{P}}, \quad \mu_{1}=-\frac{n K_{s}}{\mathcal{P}}, \quad \mu_{2}+\mu_{3}=-\frac{n W_{s}}{\mathcal{P}}, \quad \mu_{2}=-\frac{n\left(W_{s}-R_{s}\right)}{\mathcal{P}}-\frac{n \Phi}{\mathcal{P} D_{c}}
$$

using conditions (A.22)-(A.24) and $\mathcal{K}=k \mathcal{P}$. Then, using Euler's identities (A.18) and substituting $\mathcal{L}_{j}, j \in\{c ; s\}$ from (2), we have:

$$
\begin{aligned}
& \left(\frac{\mathcal{L}_{c}}{\mathcal{P}}-\mu_{3}-1\right) F_{X L}^{c}+\left(\mu_{1}+k\right) F_{K X}^{c}+\left(\mu_{2}+\mu_{3}+1\right) F_{W X}^{c}-\mu_{6}=\frac{n \Phi}{\mathcal{P} D_{c}} F_{W X}^{c} \\
& \left(\frac{n \mathcal{L}_{s}}{\mathcal{P}}+\mu_{3}\right) F_{X L}^{s}-\mu_{1} F_{X K}^{s}-\left(\mu_{2}+\mu_{3}\right) F_{W X}^{s}-n \mu_{6}=\frac{n \Phi}{\mathcal{P} D_{c}} F_{W X}^{s}
\end{aligned}
$$

Inserting (A.68)-(A.73) into each of the first-order conditions (A.42)-(A.47) entails respectively:

$$
\begin{aligned}
C_{G}^{c} & =R_{c} U_{G}^{c}+R_{c} U_{G}^{c, c}+n W_{\mathrm{sc}} U_{G}^{s, c}-\frac{n \Phi U_{G}^{s, c}}{D_{c}} \\
\tau_{c}^{R} & =\frac{t W_{c}}{n}+\frac{a W_{c}^{2}}{n^{2}}+\mathcal{P} \mu_{5}+\Phi_{\mathrm{cs}}\left(-\frac{t}{D_{c}}-\frac{a W_{c}}{n D_{c}}-\frac{n F_{\mathrm{WL}}^{c}}{D_{c}}\right) \\
\tau_{s}^{R} & =\frac{a W_{c}^{2}}{2 n^{2}}+\frac{t W_{s}}{2}+\frac{a W_{s}^{2}}{8}+\mathcal{P} \mu_{5}+\Phi\left(-\frac{t}{D_{c}}-\frac{a W_{c}}{n D_{c}}+\frac{F_{\mathrm{WL}}^{s}}{D_{c}}\right) \\
\tau_{c}^{K} & =\mathcal{P} \mu_{6}+\frac{n \Phi F_{\mathrm{WK}}^{c}}{D_{c}} \\
\tau_{s}^{K} & =\mathcal{P} \mu_{6}-\frac{\Phi F_{\mathrm{WK}}^{s}}{D_{c}}
\end{aligned}
$$

in which (A.22)-(A.24) and $\mathcal{K}=k \mathcal{P}$ have been used to collect terms. Condition (A.74) proves (34b). Moreover, inserting the taxation rules of the town (32a) and (33a) into (A.75) and (A.77) implies

$$
\begin{aligned}
& \mu_{5}=\frac{d_{s}^{R}}{\mathcal{P}}-\frac{a W_{c}^{2}}{2 n^{2} \mathcal{P}}+\frac{a W_{s}^{2}}{8 \mathcal{P}}+\Phi\left(\frac{1}{\mathcal{P}}+\frac{t}{\mathcal{P} D_{c}}+\frac{a W_{c}}{n \mathcal{P} D_{c}}-\frac{F_{\mathrm{WL}}^{s}}{\mathcal{P} D_{c}}\right) \\
& \mu_{6}=-\frac{d_{s}^{K}}{\mathcal{P}}+\frac{\Phi F_{\mathrm{WK}}^{s}}{\mathcal{P} D_{c}}
\end{aligned}
$$




\section{Appendix}

Finally, eliminating $\mu_{5}$ and $\mu_{6}$ from (A.74) and (A.77), and collecting terms proves conditions (32b) and (33b). 


\section{IdEP Economic Papers}

The series IdEP Economic Papers, ideally continues the work of the "Quaderni della Facoltà" the publication of which began in 1998 and ended in 2013.

For a complete list of the Quaderni see: http://econpapers.repec.org/paper/lugwpaper/

IdEP Economic Papers also gathers the legacy of the CEPRA Working Papers, published from 2012 to 2013

The full list at: http://econpapers.repec.org/paper/lugwcepra/

2014:

No. 01

F. Mazzonna, F. Peracchi, Unhealthy retirement? Evidence of occupation heterogeneity

No. 02

L. Di Giorgio, M. Filippini, G. Masiero, The relationship between costs and quality in nonprofit nursing homes

No. 03

F.C. Billari, V. Galasso, Fertility decisions and pension reforms : evidence from natural experiments in Italy

No. 04

M. Jametti, M. Joanis, Elections and de facto expenditure decentralization in Canada

No. 05

M. Jametti, Weathering the global financial crisis : is direct democracy of any help?

No. 06

U. Pagano, M. Vatiero, Costly institutions as substitutes : novelty and limits of the Coasian approach

No. 07

R. Parchet, Are local tax rates strategic complements or strategic substitutes?

No. 08

R. Ippoliti, M. Vatiero, An analysis of how 2002 judicial reorganization has impacted on the performance of the First Instance Courts (Preture) in Ticino

No. 09

F. Mazzonna, P. Salari, Short term effects of public smoking bans on health 
2015:

No. 01

S. Galletta, Direct democracy, partial decentralization and voter information : evidence from Swiss municipalities

No. 02

I. Sarman, Second homeowners' intention to move : an integrated ordered logit model with latent variable

No. 03

M.J. Roe, M. Vatiero, Corporate governance and its political economy

No. 04

M. Filippini, M. Koller, G. Masiero, Competitive tendering versus performance-based negotiation in Swiss public transport

No. 05

O. Giuntella, F. Mazzonna, If you don't snooze you lose health and gain weight : evidence from a regression discontinuity design

No. 06

M. Filippini, B. Hirl, G. Masiero, Rational habits in residential electricity demand

2016:

No. 01

S. Galletta, Law enforcement, municipal budgets and spillover effects : evidence from a quasiexperiment in Italy

No. 02

S. Galletta, A. Redonda, Corporate flat tax reforms and businesses'location choices. Evidence from Switzerland

No. 03

M. Filippini, W. Greene, G. Masiero, Persistent and transient productive inefficiency in a regulated industry: electricity distribution in New Zealand 
No. 04

M. Vatiero, On the (political) origin of "corporate governance" species

No. 05

E. Gentili, G. Masiero, F. Mazzonna, The role of culture in long-term care

No. 06

M. Vatiero, Learning from the Swiss corporate governance exception

No. 07

F. Cavalcanti, G. Daniele, S. Galletta, Popularity shocks and political selection : the effects of anti-corruption audits on candidates' quality

2017:

No. 01

P. Bello, Exchange rate fluctuations and border crossings : evidence from the Swiss-Italian border

No. 02

E. Gentili, F. Mazzonna, What drives the substitutability between native and foreign workers? Evidence about the role of language

No. 03

G. Daniele, S. Galletta, B. Geys, Abandon ship? Party brands and politicians' responses to a political scandal

2018:

No. 01

G. Masiero, F. Mazzonna, O. Verbeek, What drives the rise of antidepressant consumption? Evidence from Switzerland

No. 02

U. Pagano, M. Vatiero, Positional goods and legal orderings 
2019:

No. 01

G. Masiero, M. Santarossa, Earthquakes, grants and public expenditure : how municipalities respond to natural disasters

No. 02

G. Masiero, F. Mazzonna, S. Steinbach, O. Verbeek, The effect of local growth in antidepressant consumption on mental health outcomes

No. 03

T. Ly, Taxes, traffic jam and spillover in the metropolis 